\title{
Innovations for reaching the green sustainable development goals -where will they come from?
}

\author{
Rainer Walz ${ }^{1}$ - Matthias Pfaff ${ }^{1}$. \\ Frank Marscheider-Weidemann ${ }^{1}$. \\ Simon Glöser-Chahoud ${ }^{1}$
}

Published online: 5 July 2017

(C) The Author(s) 2017. This article is an open access publication

\begin{abstract}
Reaching the sustainable development goals needs innovations. This paper addresses the dynamics of green energy and resource efficiency innovations, and looks at the positioning of countries from the North and emerging economies. We use indicators for both general innovation capabilities and specific green technology capabilities. Data on general innovation capabilities reveal that the traditional OECD countries, by and large, still possess advantages compared to Newly Industrializing Countries (NICs). Literature and Patent indicators reveal that the innovation dynamics are particularly high for publications. Literature and exports indicators reveal that the South has been catching up substantially. With regard to patents, some countries of the South are catching up, but the North is still cleary leading. A detailed analysis of copatenting and country-to-country trade data reveals a more differentiated picture: Leading countries from Europe such as Germany as still specializing on serving the markets of traditional OECD countries. Japan and Korea are very reluctant with regard to co-patenting, but specialize in exporting to China. South-South trade in green technologies is the fastest growing market segment. However, countries of the South are pursuing a differentiated strategy: Mexico is highly integrated into the US economy. Singapore and South Korea have been catching up and provide technologies especially for China. China itself is following a double strategy, with absorbing technology from the North in order to compete on markets of the North on the one hand, but increasingly specializing on becoming lead supplier for countries of the South on the other hand. The other technology providers from the South are mainly specializing in supplying other countries from the South. Thus, a segmentation of the market is likely, with green sustainability innovations in the South more likely originating in the South as well, and
\end{abstract}

Rainer Walz

rainer.walz@isi.fraunhofer.de

1 Fraunhofer Institute for Systems and Innovation Research, Karlsruhe, Germany 
China being an important country to adapt knowledge from the North to the needs of the South.

Keywords Sustainable development goals · Innovation indicators · Green patents · Green exports · Market segmentation

\section{Introduction}

After deciding on the Sustainable Development Goals (SDGs) in the post Rio + 20 process, and after the Paris Agreement, innovations to reach the SDGs have gained in importance in policy debates. This paper concentrates on the SDGs related to the environment. Environment-related goals such as water quality, climate and living on land (SDG No. 13 to 15) are highly related to providing necessary access to energy and safe drinking water (SDG No. 7 and 8), which in itself is a key to improving the health situation (SDG No. 3). All this is tied to the future of cities and infrastructures (SDG No. 9 and 11), with consumptions patterns interacting with production (SDG No. 12). Most clearly, the markets for green technologies will also provide opportunities to create new jobs (SDG No. 8). Indeed, the projections in this field show a substantial increase in the past, which is projected to continue. And all this is tied to development perspectives of the North and South, with regard to reducing inequalities within and between generations (SDG No. 10).

The policy debate has put high hopes into technology transfer from North to South, especially with regard to low carbon technologies. Indeed a lot of negotiations around the Paris agreement dealt with questions about how to finance such a transfer. At the same time, economic and inclusive development requires that countries of the South increasingly develop their own capabilities. Innovation scholars have emphasized that development of technologies co-evolves with their socio-economic environment, and have pointed out the importance of building systems which enhance innovations, competence building and learning.

However, what is the stage of development of building such systems for environmental innovations? Will enough innovations be generated to reach the green SDGs? And where will they be generated - are the innovations more likely to come from the North as in the past, or will we see a new pattern of innovation generation with an increased or perhaps leading role of the South?

This paper aims to look at existing empirical evidence. In section 2 , we introduce the methodological background for our empirical study, which is based on various innovation indicators. In section 3, we look at the positioning of countries with regard to general innovation capabilities. This requires national comparisons of the capabilities of the countries. In section 4, we look at technology specific capabilities for green innovations. We analyze the innovation dynamics on the one hand, but also the positioning of countries on the other. In section 5, we turn towards the issue whether the innovations are dominated by one paradigm which puts emphasis on implementing cutting edge knowledge, or if there is also an indication that regionally segmented markets for green technologies are emerging. Finally, the discussion and conclusions of the analysis will be presented in section 6. 


\section{Methodological background}

\subsection{The need for innovations in the north and south}

The role of innovations in preventing global ecological disaster has been embedded in North-South economic development from early on. According to the Environmental Kuznets Curve (EKC)-hypothesis, environmental pressure grows faster than income in a first stage of economic development. This is followed by a second stage in which environmental pressure still increases but more slowly than GDP. After a particular income level has been reached, environmental pressure declines despite continued income growth. However, the literature has pointed our several critical aspects of this concept. First, the existence of an EKC is far from certain. It may hold better for local environmental effects than global ones (Ekins 1997; Dinda 2004; Galeotti et al. 2006). Furthermore, even if such a development can be seen in the developed world, it might just reflect a displacement effect of dirty industries to other less developed countries. Finally, there is clear evidence that such a development does not occur naturally, but requires active policies and regulations and an appropriate institutional setting (Dutt 2009). Within the global environmental debate, it is argued that NICs do not necessarily have to follow the pollution path of the industrialized countries. Assuming the existence of an environmental EKC, an alternative development path has been labelled "tunnelling through the EKC" (Munasinghe 1999; Gallagher 2006). This concept argues that countries catching up economically can realize the peak of their EKC at a much lower level of environmental pressure than the developed countries, because they can draw on the experience of industrialized countries allowing them to use the latest sustainability technologies. This leads to a "strategic tunnel" through the EKC. Here, environmental economists put faith into quick technological development in the North and knowledge transfer as a key for reconciling environmental sustainability with economic development in the South. Implicitly, it is taken for granted that cutting edge technologies developed in the North will be used in the South. Thus, key issues seen within this concept are the question of how to finance the transfer of the latest technologies from the countries of the North to NICs, including policy concepts such as climate funds.

Walz and Marscheider-Weidemann (2011) summarized the results of the research on technological development in the South and the factors which influence the build-up of their technological competences. Since the end of the 1980s, the concepts of Social or Absorptive Capacity (Abramovitz 1986; Cohen and Levinthal 1990) and technological capabilities (Lall 1998; Bell and Pavitt 1993) are widely known. The results of the research on technological development in NICs and the factors which influence the build-up of their technological capabilities (e.g. Fagerberg and Godinho 2005; Nelson 2007; Malerba and Mani 2009; Lall 1998; Lee 2005; Rasiah 2008) have underlined the importance of absorptive capacity and competence building. Studies analyzing these developments have to take into account the changing conditions for learning and knowledge acquisition. One aspect to consider is the tendency that the build-up of technological and production capabilities is increasingly separated (Bell and Pavitt 1993). Another aspect relates to the effect of globalization on the mechanisms for knowledge dissemination. Archibugi and Pietrobelli (2003) stress the point that importing technology has per se little impact on learning and call for policies to 
upgrade cooperation strategies towards technological partnering. Nelson (2007) highlights the changing legal environment and the fact that the scientific and technical communities have moved much closer together. All these factors lead to the conclusion that domestic competences in sustainability related science and technology fields are increasingly a prerequisite for the successful absorption of green technologies in NICs.

There are some arguments which point towards the conclusion that sustainability innovations emerge primarily in the North: In general, the framework conditions for innovations are seen as superior in the North. In addition, environmental quality is characterized as a superior economic good with high income elasticity of demand. Thus, lead users for sustainability innovations would be typically found in high income countries (Quitzow et al. 2014) Furthermore, the externalities, especially of global environmental aspects, make environmental policy a prerequisite, which is also more likely to be found in high income countries. In contrast, with scarce public funds and pressing domestic short term needs, it is questionable whether environmental problems make it to the top lists of challenges to be tackled early on in the South. Iizuka (2015) points out that in developing countries the rival issue of catching up has often higher priority than environmental sustainability. On the other hand, there are also arguments for countries of the South promoting green innovations early on (Walz and Köhler 2014; Köhler et al. 2014): Environmental problems are increasingly seen as a stumbling block in the economic development of the South, especially with regard to the health effects associated with them. The markets for green technologies might also offer opportunities; thus the interaction of economic and environmental interests might lead to a - perhaps uneven - transition path (Iizuka 2015). Existing path dependencies are a strong obstacle especially to green innovations related to infrastructure (Walz 2007), and such path dependencies are much more likely to be more pronounced in the North. Finally, innovations require adaptations and take place in a co-evolution between technology and socio-economic environment. It is argued that especially countries from the South have advantages in developing innovations which are suited for the South. Thus, from a conceptual basis, there are mixed arguments for whether or not innovations for the green SDGs will primarily evolve in the North, or whether countries of the South will be catching up or even leapfrog to the top.

Research on the role of geographical diversification for the management of companies' export strategies has addressed this issue from an additional perspective. On the one hand, commentators argue that factors in the destination country, e.g. its physical infrastructure, are important for the exporting firm (Hoskisson et al. 2013). Thus, the functions an export good has to fulfill must fit the conditions of the country of destination. Green technology markets increasingly grow in developing countries. This requires that the technologies are adapted to the specific needs, which are characterized by lower framework conditions. This can imply that a more downsized good is needed, which is only able to deliver the most basic functions in a low factor environment. Lately this strategy has been also discussed under the label of frugal innovations (Agarwal and Brem 2012; Tiwari and Herstatt 2012). Designing such a good requires, however, not the typical cutting edge technological capabilities, but the ability to understand the low factor environment and to adapt the product to it. On the other hand, from an institutional framework perspective the capability to serve a foreign market is also influenced from conditions of the supplying company in both its home and destination country (Peng 2012; Hoskisson et al. 2013; Boehe et al. 2016). The home countries' institutional and factor conditions shape the resources and capabilities 
of the company. Thus, if the country of destination is characterized by weak factors and institutions, a company might enjoy an adversity advantage, because some weak conditions in its home country have enabled it to develop capabilities of succeeding under such conditions (Cuervo-Cazurra and Genc 2008; Boehe et al. 2016). Such a situation can support a segmentation of markets, with cutting edge technology provided by companies from countries with superior cutting-edge technological capabilities for a primary market, and companies adapted to a weaker factor and institutional framework supplying a secondary market. Thus, from a conceptual point of view, it is not only the technological capabilities but also the general capabilities which influence success on international markets.

Empirical studies using innovation indicators indicated that NICs have been increasing their general capabilities in the 2000s (Walz and Marscheider-Weidemann 2011), but more so specific technological capabilities. The paper is motivated by the following research questions:

- What is the positioning of countries with regard to general innovation capabilities? This requires national comparisons of these capabilities, which are addressed in section 3.

- What are the dynamics of green innovations before and after the financial crisis? Do we see that the South has been developing capabilities and thereby caught up? What countries are positioning themselves especially strongly towards green innovations? Section 4 deals with the empirical analysis of this question.

- Do we see an indication of whether the innovations are dominated by one paradigm with technological leaders and followers, or is there also an indication that segmented markets for sustainability technologies are emerging, which in addition to a Northern segment also account for a paradigm which more strongly draws on coevolution of technologies and a socio-economic environment specific to the South? Section 5 is devoted to that research question.

\subsection{Methodology}

Green innovations require good framework conditions for innovations in general. Unless some level of sophistication is reached with regard to technological readiness and innovation capabilities, specific policy strategies will not be successful. The analysis of general capabilities for sophisticated technologies and innovations draws on data from the World Economic Forum (WEF 2015), which has constructed various indices on economic and innovation factors. Rennings (2000) has argued that the double externality problems results in environmental innovations depending heavily on environmental policy. Thus, we include indicators about governance. The general capabilities necessary for good governance are often characterized based on indices of corruption and good governance. We draw on the corruption perception index of Transparency International, which ranks countries based on how corrupt their public sector is perceived to be, and data from the World Bank, which collects a dataset summarizing the views on the quality of governance.

In addition to general capabilities, specific competences for sustainability technologies are required. Innovations in environmental technologies have to be defined in order to be analyzed with indicators. The following technological fields were included 
under the heading of green technologies: (1) energy efficiency, (2) environmentally friendly energy supply technologies, (3) material efficiency and waste management, and (4) water technologies. Thus, we cover the central technological fields which make up low carbon and resource efficiency. Table 1 shows the relationship between the technological fields and the SDGs. Given the environmental focus of our paper, not all of the SDGs are directly addressed. Nevertheless, there is a direct relation between technologies and SDGs for 11 out of the 17 SDGs. In general, the technological fields relate to various SDGs, and vice versa. Thus, specializations of countries in specific technology classes do not necessarily indicate an emphasis on a specific SDG or a division of labor between the countries to achieve the SDG.

The measurement of technological capabilities can draw on the experience with innovation indicators made over the last two decades (see Grupp 1999; Smith 2005; Freeman and Soete 2009). Patents are among the most used indicators in this kind of research. They belong to the intermediate output indicators of knowledge build-up and are directly related to technological capabilities. The choice of patent offices from which applications are taken is especially tricky for country comparisons, since patents also serve to protect markets, and it is therefore widely known that there are significant country biases in favor of domestic applicants which give highest priority to protect home markets. In order to account for country bias, the triadic patent approach has been developed in the 1990s, which takes only patents into account which are applied for at the EPO, USPTO and JPO at the same time. Frietsch and Schmoch (2010) point to different methodological problems with this approach, especially with regard to difficulties in accounting for the effects of new players emerging on the international stage. Thus, Frietsch and Schmoch (2010) developed a transnational patent approach, which is also used for this paper. This approach counts all PCT applications whether transferred to EPO or not, and all direct EPO applications without precursor PCT application. Thus, all patent families with at least a PCT application or an EPO

Table 1 Main relation between selected technology classes and SDG

\begin{tabular}{ll}
\hline Technological field & SDG \\
\hline Energy efficiency & Good health and well-being (No. 3) \\
& Affordable and clean energy (No. 7) \\
& Industry, innovation and infrastructure (No. 9) \\
& Climate action (no. 13) \\
Green energy supply & Affordable and clean energy (No. 7) \\
& Industry, innovation and infrastructure (No. 9) \\
& Sustainable cities and communities (No. 11); \\
& Climate action (no. 13) \\
Material efficiency and waste management & Good health and well-being (No. 3) \\
& Industry, innovation and infrastructure (No. 9) \\
& Sustainable cities and communities (No. 11) \\
& Responsible consumption and production (No. 12) \\
& Life on land (15) \\
& Good health and well-being (No. 3) \\
Clean water and sanitation (No. 6) & Sustainable cities and communities (No. 11) \\
Life below water (No. 14)
\end{tabular}


application are taken into account. After testing and comparing different approaches, Frietsch and Schmoch (2010) conclude that this transnational approach provides larger samples than the Triadic approach for the analysis of specific fields, and is capable of grasping the relationships between different countries more reliably. In this way, a method of mapping international patents is employed which does not target individual markets but is much more transnational in character. The patents identified in this way reveal those segments in which patent applicants are already taking a broader international perspective. The available data were retrieved from the PATSTAT database. The latest year available for the analysis was 2013. Earlier periods for patents were used to describe the increase in patenting over the years. In order to retrieve additional information on cooperation patterns, we also performed an analysis of co-patenting.

Publication data (number of peer-reviewed journal publications) is also a highly common indicator used for measuring and comparing research activities in the different technological fields (Grupp 1999; Smith 2005). Data are taken from Web of Science (WoS). The latest year, for which reliable data was available, was 2014.

In order to measure countries' performance with regard to bringing innovation technologies to the market, we look at export data. International trade figures indicate the degree to which a country is able to compete internationally for specific technologies. The database UN-COMTRADE serves as the source for trade figures. The classification of the technologies is based on the Harmonized System (HS) 2002. This foreign trade classification allows a higher disaggregation and therefore a better targeting of the sustainability technologies compared with the older classifications common in international comparisons (Standard International Trade Classification SITC). The latest year available for the analysis was 2013. The trade data can be used to look at the performance of a country on the world market. On a more disaggregated level, it can be used to look into more detail at how a country performs in trade with all other countries. Both levels of analysis are covered within this paper. Especially the addressing of the research question requires country-to-country trade data.

For patents, publications and world trade, the selected countries' share of the world total was calculated (patent share, publications share, world trade share). In order to account for the different sizes of countries, we calculated export shares of GDP and patent and publications intensities per million inhabitants. Furthermore, specialization indicators such as relative patent advantage (RPA), relative literature advantage (RLA), and relative export activity (RXA) were calculated, in order to analyze whether or not the countries specialize in sustainability technologies.

For every country $i$ and every technology field $j$ the Relative Patent Activity (RPA) is calculated according to: $\mathrm{RPA}_{i j}=100^{*} \tanh \ln \left[\left(p_{i j} / \sum_{i} p_{i j}\right) /\left(\sum_{j} p_{i j} / \sum_{i j} p_{i j}\right)\right]$ i. e. the RPA relates the number of patents $p$ for a given technology $j$ in a country $i$ to the worldwide patents for this technology. This ratio is then compared with the same ratio for all technologies.

The RLA and the RXA are calculated in a similar way as the RPA, by substituting patents $(p)$ by publications $(l)$ and exports $(x)$, respectively. All specialization indicators are normalized between +100 and -100 (see Grupp 1999). Positive values indicate an above average specialization in the analyzed technology; negative values show that the country is specializing more in other technologies. 
In order to analyze market segmentation strategies, we looked at patent collaboration and at country-to-country trade data capturing regional market segments. The copatenting patterns reveal which countries are especially forging links with regard to knowledge sharing. Country-to-country trade data allows for the identification of those markets which are especially targeted by a country. Thus, the export shares were calculated for single countries or country groups. In order to indicate the specialization of a country in different regional segments, a regional export share index was calculated, which is also normalized between -100 and +100 .

For every country $i$ and every market segment $j$ the Relative Trade Specialisation (RTS) is calculated according to: $\operatorname{RTS}_{i j}=100^{*} \tanh \ln \left[\left(x_{i j} / \sum_{i} x_{i j}\right) /\left(\sum_{j} x_{i j} / \sum_{i j} x_{i j}\right)\right]$ i.e. the RTS relates the country's share of exports to a specific region to the country's export share of world exports.

Green technologies are neither a patent class nor a classification in the HS-2002 classification of the trade data from the UN-COMTRADE database or a WoS classification which can be easily extracted. With regard to patents, many technologies which fall under the heading of the technology classes mentioned above form specific international patent subclasses (IPC); they are also included in recent approaches to define standardized classifications recently, such as the Y02 of EPO, or the IPC Green Inventory of WIPO. However, both of these classification schemes still do not account for important technologies, especially with regard to cross-cutting and process specific energy efficiency technologies. Furthermore, our technology classes encompass much more than only energy related technologies. Thus, for patents and publications, we use the Fraunhofer ISI sustainability technology database, which also uses specific key word based search strategies in order to derive patents for resource efficiency which do not form a separate patent subclass (see Walz and Marscheider-Weidemann 2011). With regard to trade data, there is a separate 6-digit level for some technologies. For other technologies, it was necessary to identify the key technological concepts and segments. They were transformed into specific search concepts for the publication, patent and trade data. This required substantial engineering skills. Furthermore, there is a dual use problem of the identified segments: the data only indicate that there is a technological capability which could be used for sustainability innovation - not necessarily that these technologies are already implemented in a way that the environmental burden is reduced. Thus, in order to reflect that ambiguity, the terms "green innovation" or "green technology", which are used in the text, have to be interpreted as potentially relevant technologies for reaching the green SDGs.

With regard to country coverage, we have selected a 32 country sample for performing the analysis in sections 3 and 4. These countries consist of OECD countries and Newly Industrializing Countries (NICs). From this sample, we formed country clusters that deviate slightly from the established categories. Thus we distinguish between "traditional OECD" countries on the one hand, and other countries for which we use the label "Newly Industrializing Countries", on the other. The latter category contains some countries which actually belong to the OECD (e.g. South Korea, Mexico), which makes it difficult to label them as "the South". In section 5, the data covers trade between all countries listed in the UN-COMTRADE. However, selected countries with specific importance for the overall development are also depicted in more detail. 


\section{General capabilities}

\subsection{General capabilities for sophisticated technologies and innovations}

The general capabilities necessary for sophisticated technologies and innovations (and hence also important for green SDGs) are often characterized based on input indicators in terms of $R \& D$ intensity ( $R \& D$ expenditures at the national level and by industry, related to the Gross Domestic Product GDP). The quantitative data on innovation capacity give a first indication of the general research conditions for innovation. The national $R \& D$ intensity is rather different among the country sample. It reaches from very small numbers far below $1 \%$, e. g. for Indonesia or the Philippines, to values between 2 and 3\% - which are typical for some advanced NICs, e. g. for Singapore, Taiwan or South Korea, or traditional OECD countries.

Instead of looking at single quantitative indicators alone, the results of World Economic Forum (WEF 2015 are used, which use two composite indicators: one for technological readiness, which indicates the ability of countries to adopt existing technologies which enhance the productivity of its industries, and another one for innovation capability, which accounts for the availability of innovation financing and research institutions, among others. This data is based on the Opinion Survey of WEF, using a scale between 0 and 7 . The results indicate that newly industrializing countries, in general, still have lower innovation capabilities (Fig. 1). However, some of the newly industrializing countries have been moving up, and have closed the gap.

\subsection{Governance}

Transparency International builds a composite index which draws on corruptionindicators collected by a variety of institutions. The higher the index value, the less

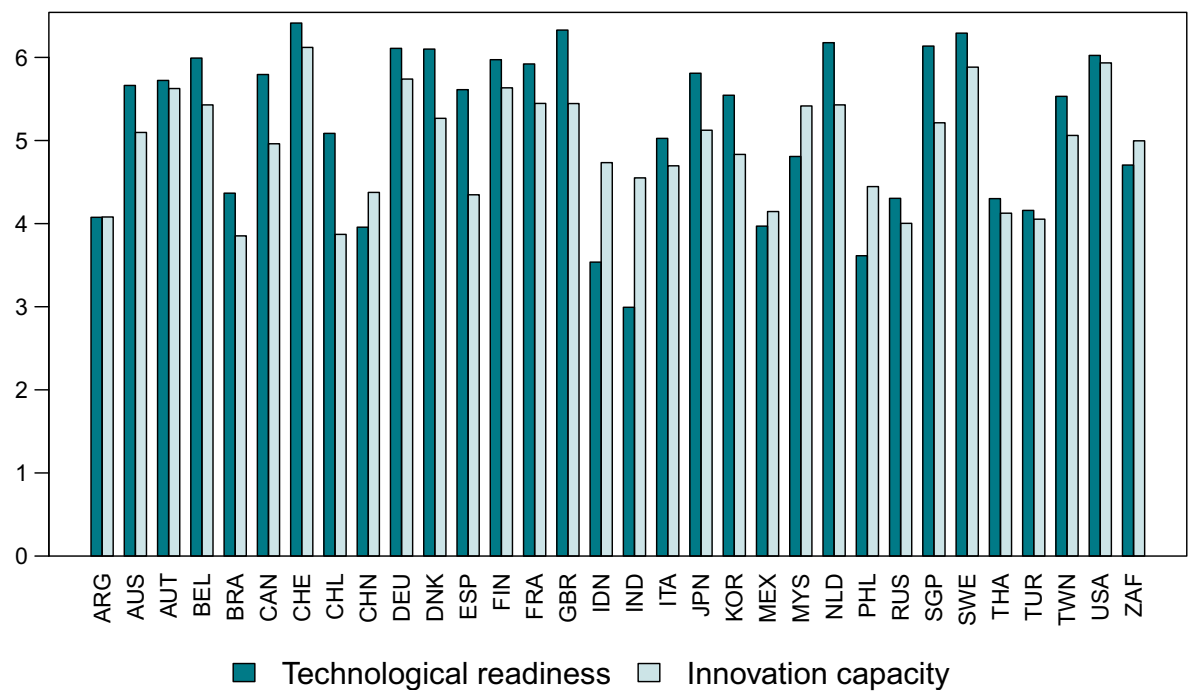

Fig. 1 General innovation capability and technological readiness in selected countries. Source: Data from WEF 2015 
prevailing is corruption perceived to be. This index is normalized between 0 and 100 . Furthermore, we look at data from the World Bank, which collects a dataset summarizing the views on the quality of governance provided by a large number of enterprise, citizen and expert survey respondents in industrial and developing countries. The data of the World Bank covers different aspects of governance, and is normalized between 0 and 100 . We build the average of the subset for the three areas "voice and accountability", "political stability/no violence", and "government effectiveness", and use it as a composite index.

The results of these indicators show that newly industrializing countries, in general, have lower indicator values for both the World Bank governance and the Transparency International Corruption Prevention Indicator (Fig. 2). Thus, as may be expected, empirical data indicates that general capabilities with regard to governance are less developed in emerging economies.

\subsection{Stringency and enforcement of environmental policy}

Many of the widely debated policies to foster green innovations - e.g. emissions trading, feed-in-tariffs or environmental standards - are necessary to achieve diffusion of green technologies. Thus, there is a clear difference to other "normal" innovations: It is not (only) the lead users, which are important for new preferences to be shaping a market, and which support innovations via user-producer interrelationships. The demand for green innovations must be initiated by some form of environmental regulation. This does not necessarily involve public spending or public procurement. Thus, the stringency with which the countries pursue environmental targets, and the enforcement of environmental policy, also act as general framework conditions for successful demand stimulation within the innovation system. Various studies have shown that these factors are crucial for inducing innovation effects towards new or improved sustainability technologies.

We use the data from the World Economic Forum Opinion Survey (2015). This data uses a scale between 0 (no stringency/enforcement) and 7 (high stringency/

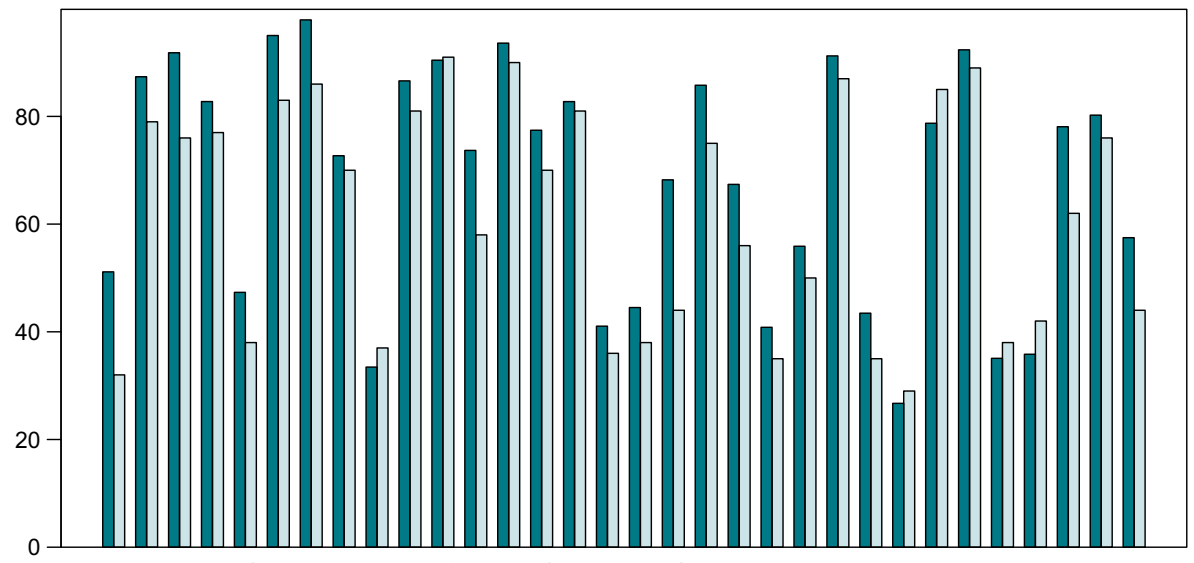

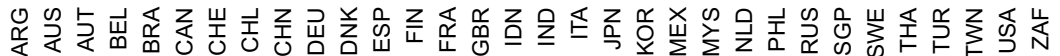

Governance

$\square$ Corruption prevention

Fig. 2 Indicators on general governance capabilities and corruption prevention for selected countries. Source: Data from World Bank and Transparency International 2015 
enforcement). By and large, traditional OECD-countries still show a higher stringency and higher level of enforcement of environmental policy than NICs (Fig. 3).

\section{Green innovation capabilities}

\subsection{Publications}

Scientific publications belong to the intermediate innovation indicators, which show the level of knowledge creation. The development of publications can be used as an indicator for the change in the importance of scientific fields over time. Figure 4 shows the publication dynamics in the field of the green technologies, compared with the dynamics of all publications covered by WoS. It can be seen that publications on green technologies show much higher dynamics than the average of all publications, and have been accelerating after 2004. This increase in dynamics has been especially strong in the NICs. This has resulted in a strong increase of the share of the publications from the NICs (Fig. 5). Indeed, in 2014, about half of all publications came from the NICs. Clearly, it can be argued that the topic of green technologies is increasingly taking a hold in the scientific community of NICs.

The analysis of the 32 countries reveals that the major part of this increase in the share of NICs can be attributed to China, which almost accounts for one quarter of the green technology publications (see Fig. 20 in the annex). In contrast, the US has lost its leading position and accounts for another $15 \%$. Other major countries are Germany, Korea, Japan, UK and Italy, with about $5 \%$ world share each.

In addition to its emphasis on a technological field, a country's share reflects also the size of the country and its general orientation with regard to publishing in journals covered by WoS. In order to adjust for different country sizes, we also calculate the publication intensity. The publication intensity is highest in Denmark, followed closely

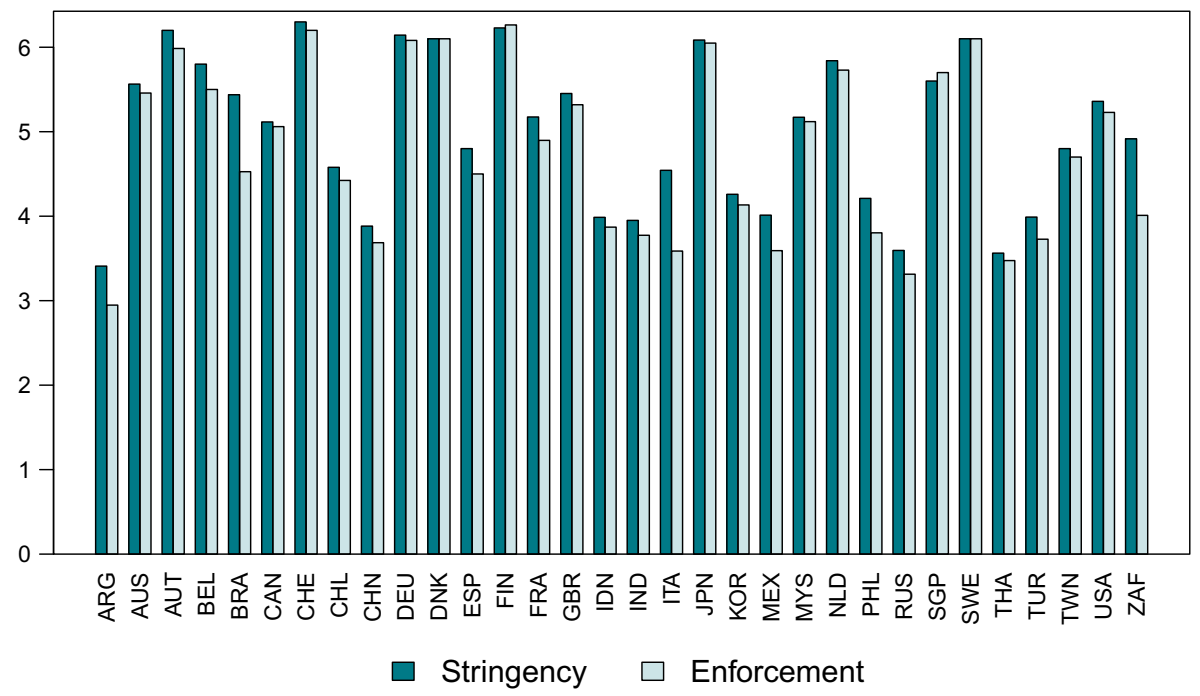

Fig. 3 Stringency and enforcement of environmental policies. Source: data from WEF 2015 


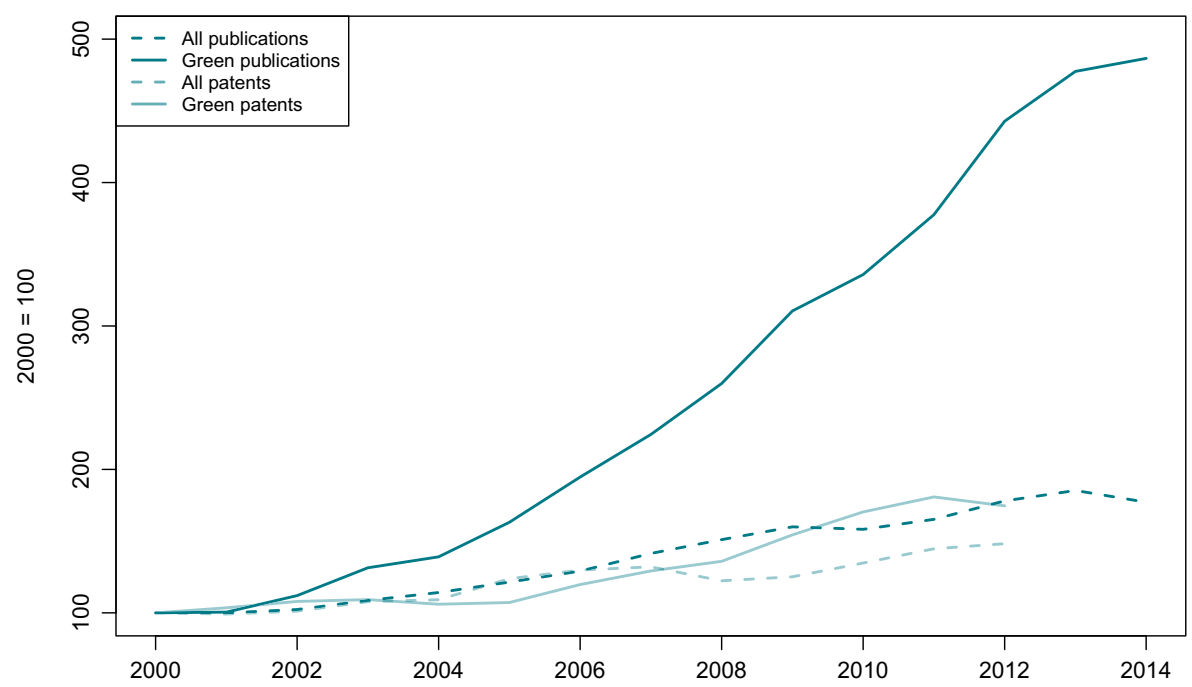

Fig. 4 Dynamics of publications and patents. Source: own calculation, based on data retrieved from WoS and PATSTAT

by Singapore, Switzerland and Sweden. Taiwan and Korea also achieve values which are above most traditional OECD countries. The values for the other NICs, however, show that there still is considerable distance to catch up with traditional OECD-intensities (Fig. 6).

In order to also adjust for the overall level of publication propensity in the countries, we look at the publication specialization. In general, the specialization within the OECD countries has been reduced; most of them show a negative literature specialization. The development within the NICs has not been homogenous, however. Some have been increasing their specialization, others not. However, all of the Asian NICs show a

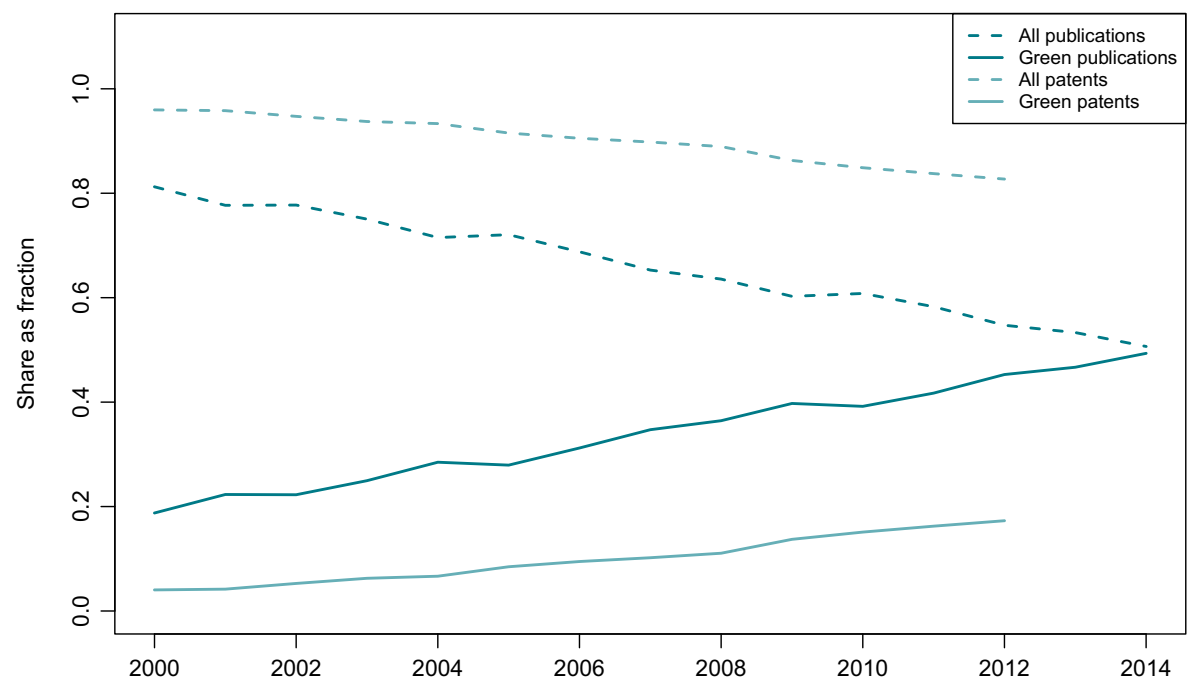

Fig. 5 Development of shares of North and NICs in green technology publications and patents. Source: own calculation, based on data retrieved from WoS and PATSTAT 
positive specialization. Thus, especially Asian countries seem to be the ones in which academic research systems have been taking up the environmental challenges (Fig. 7).

\subsection{Patents}

Next to publication dynamics, Figure 4 shows the patent dynamics in the field of green technologies, compared with the dynamics of all patents. By and large, the dynamics have been the same until 2007. Since 2007, the dynamics in green technologies have been exceeding the average. This increase in dynamics has been especially strong in the NICs (see Fig. 5). This has resulted in a quadrupling of the share of the patents from the NICs. However, with a share of $4 \%$ in 2000 , the starting point of the NICs has been much lower compared to their share in publications. Thus, the share of the NICs in patents in 2012 was still below their share in publications in 2000. Clearly, it can be argued that the topic of green technologies is increasingly taking a hold in the community of NICs, but the level is still much lower than in the North.

The analysis of the 32 countries reveals that the major part of this increase in the share of NICs can be attributed to China (plus 5 percentage points), Korea (plus 4 percentage points), and India (plus 1 percentage points). Among the traditional OECD countries, Japan has been increasing its share substantially. The US and Germany have lost shares, but are still clearly No. 2 and 3, respectively (see Fig. 21 in the annex).

In order to adjust for country size, we calculate the patent intensity per million of inhabitants (Fig. 6). The highest intensity can be found in Finland, Denmark and Switzerland. Austria, Germany, Japan and Sweden also show considerably high patent intensities. With the exception of Korea and Singapore, the patent intensity of the NICs is considerably lower than the patent intensity even of the laggards among the traditional OECD countries. Interestingly, the patent intensity is higher than the literature intensity for a couple of traditional OECD countries, especially for Austria, Finland, Germany, and Japan. In contrast, for all of the NICs, the patent intensity is

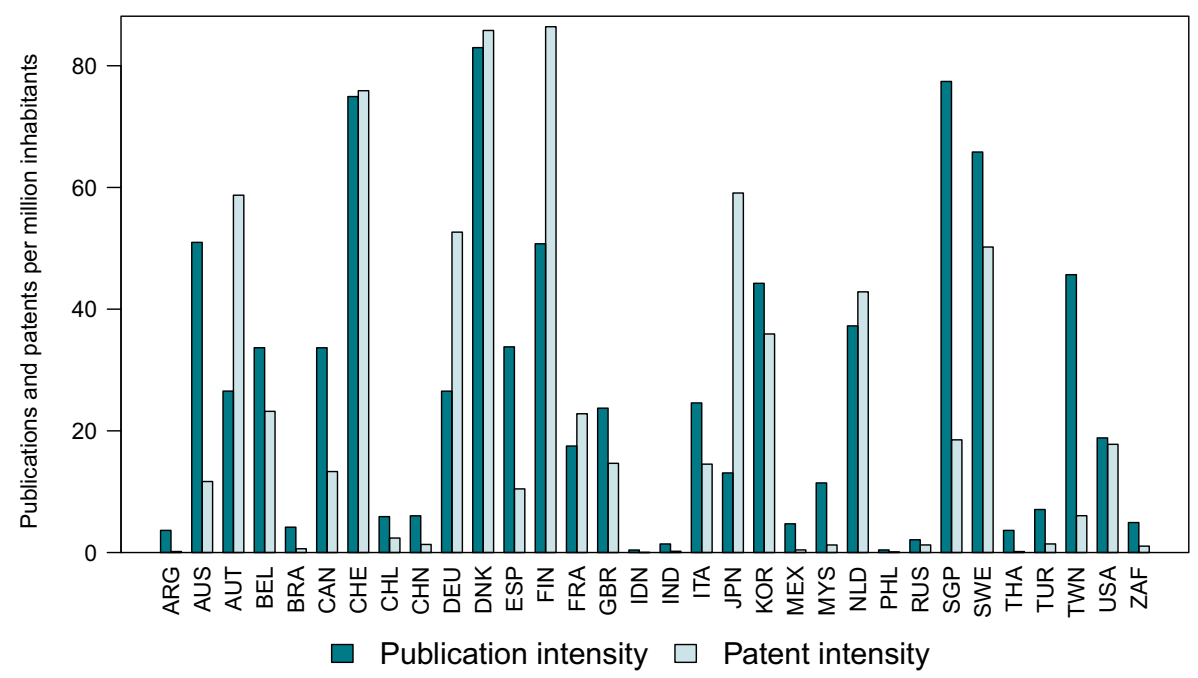

Fig. 6 Development of green technology publication and patent intensity. Source: own calculation, based on data retrieved from WoS and from PATSTAT 


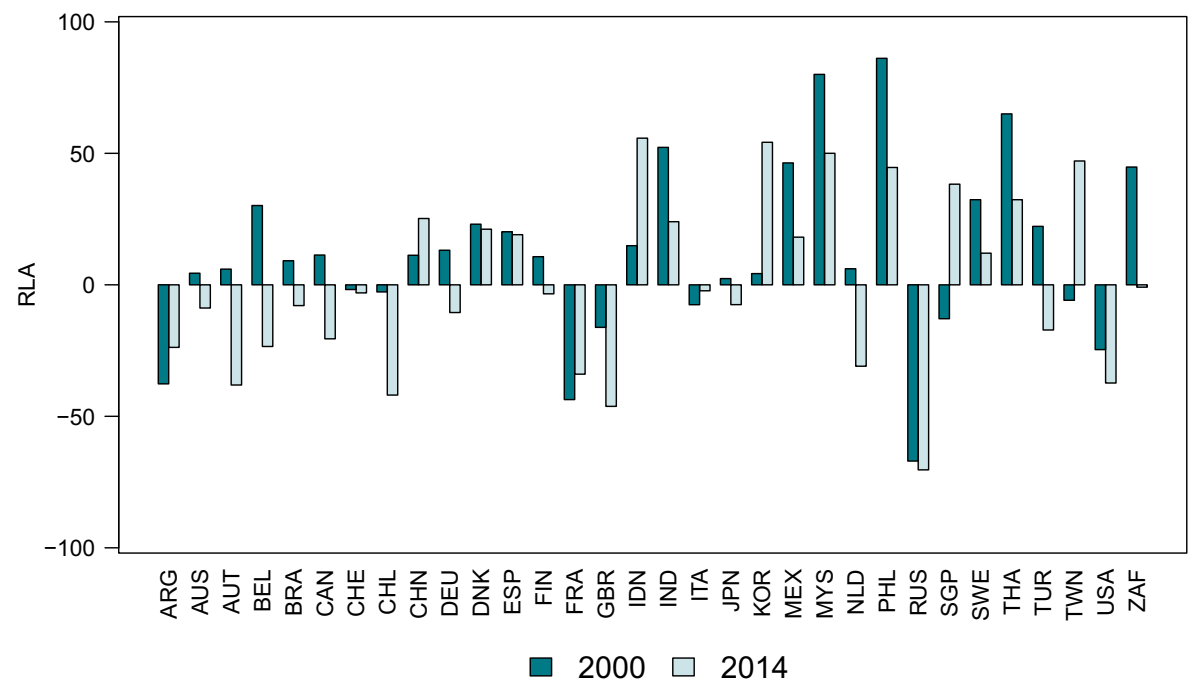

Fig. 7 Development of literature specialization of country sample in green technology publications. Source: own calculations, based on data from WoS

substantially lower than the publication intensity. Clearly, the distance between NICs and traditional OECD countries is still substantial with regard to patent output.

In order to also account for different country sizes, different developmental stages and different propensities to patent, we also calculated the RPA. Within the traditional OECD, more countries show a positive specialization than a negative one. The development has been very mixed, however, with about half of the OECD countries improving, the other half reducing their specialisation. The strongest specialization is found for Denmark, Finland and Austria. Among the large countries, Germany and Japan show a positive, the US a negative specialization. In contrast to the specialization pattern in literature, there is no clear cut patent specialization pattern among the NICs. Indeed, literature and patent specialization quite often show different signs. In contrast to the specialization pattern in literature, green technologies are not a field which has taken a particular stronghold in the Asian countries. China and India show a negative, Korea an average patent specialization. Brazil and Mexico, on the other hand, show a positive patent specialization (Fig. 8).

\subsection{Exports}

The development of green exports has been following the overall development of exports very closely. Both total and green exports more than doubled between 2000 and 2008 , were reduced by the financial crisis in 2009 , bounced up again until 2011, and have kept their level since then more or less. From the early 2000s until 2013, the share of NICs in world green exports rose from $18.7 \%$ to almost $31.6 \%$. This increase was a little bit stronger than the overall increase in NICs' share of total exports, which rose from $22 \%$ in the early 2000 s to $32 \%$ in 2013 . 


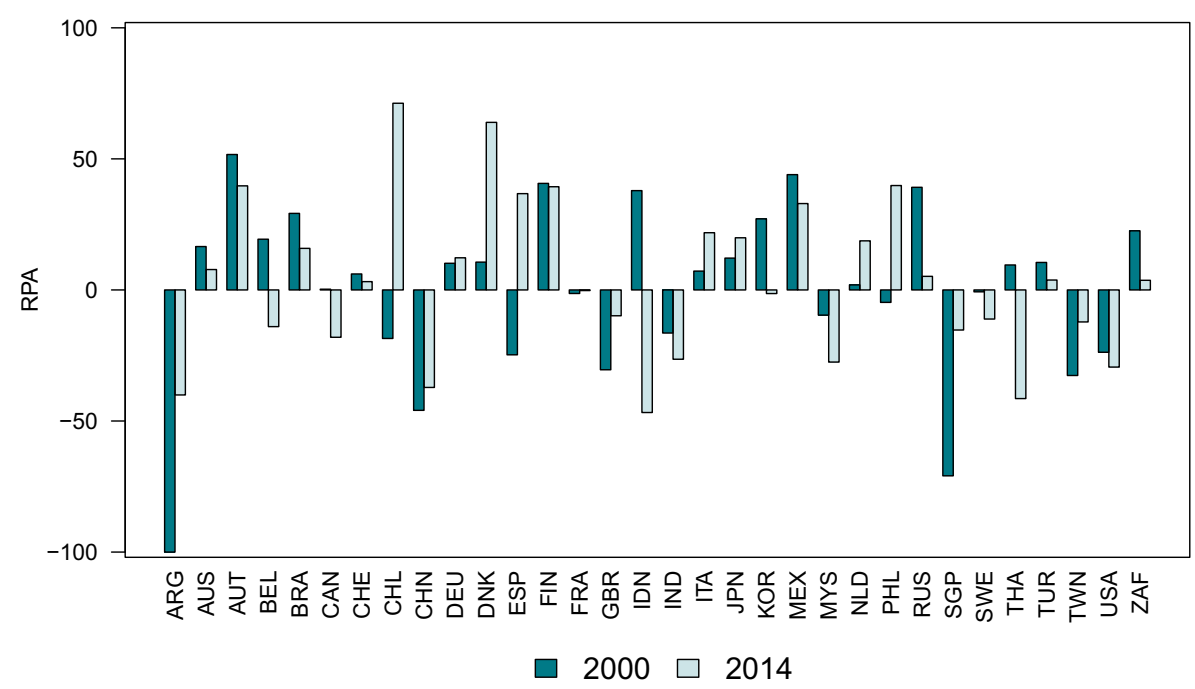

Fig. 8 Development of patent specialization of country sample in green technology patents. Source: own calculation, based on data retrieved from PATSTAT

The major exporters are Germany, China and the US, with export shares above 10\%, followed by Japan and Italy (Fig. 9). In general, the export shares are more equally distributed compared to patents and publications. In order to adjust for country size, we have calculated the export ratio of green exports to GDP of the respective country. This indicator shows the importance green exports have achieved for the economies of the respective countries. This ratio is especially high for Mexico, Singapore, and Thailand. Among the traditional OECD countries, the export oriented green industry is especially important in Austria, Belgium, Germany and Denmark.

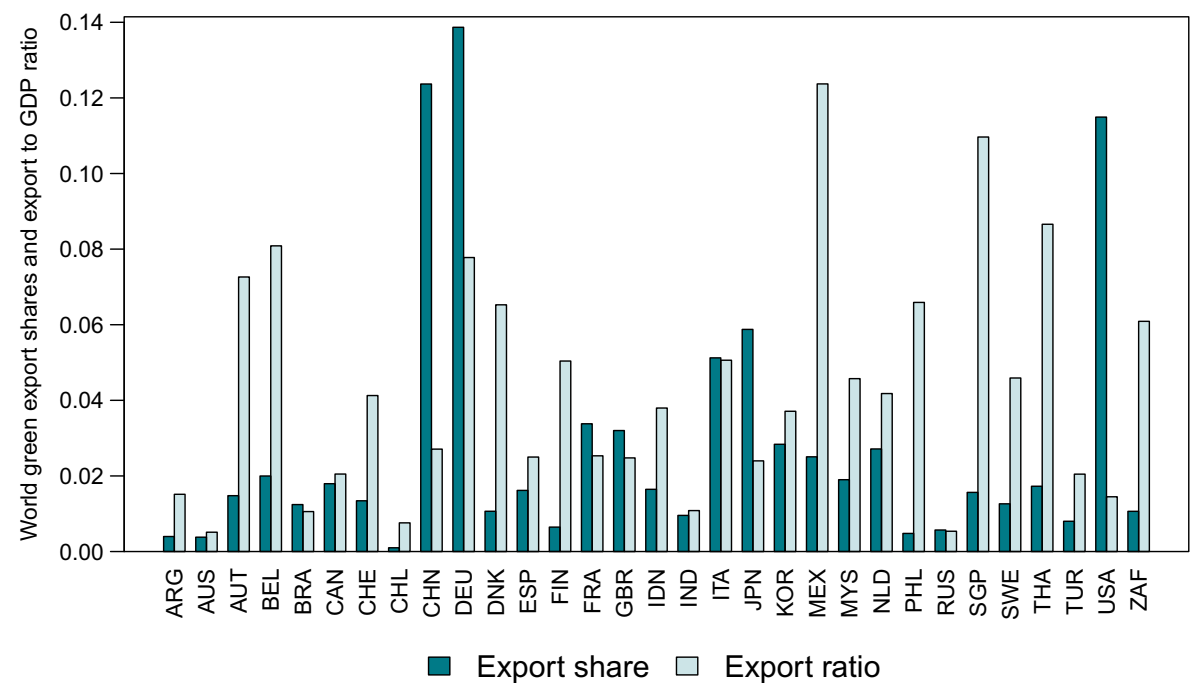

Fig. 9 World green export shares and export to GDP ratio of country sample in green technology patents. Source: own calculation, based on UN COMTRADE data 
The different export ratios are also influenced by a different openness of each respective country with regard to trade. Thus, we also calculated the export specialization, which indicates the importance of a technological field within each country compared to all other fields. The data shows that half of the analyzed traditional OECD countries show a positive export specialization. The other half has an average or negative export specialization. The situation is also heterogeneous for the NICs. Six out of 15 countries show a positive export specialization.

It is also interesting to see how export and patent specialization differ (Fig. 10). This is less the case for the traditional OECD countries, but very common for the NICs. Furthermore, it has to be kept in mind that the comparative level of patenting in NICs is lower than for exporting. All this implies that it seems to be possible to be successful in exporting without building up an above average pool of domestically generated technological knowledge. This underlines the importance of the manifold channels of technology transfer, i.e. innovation partnerships, licensing, FDI and embodied capital. Furthermore, another possibility might be that NICs are able to achieve their export success with a different strategy which builds less on cutting edge technological knowledge. It is these sorts of questions to which we turn in section 5.

\section{Market strategies}

The previous analysis implicitly assumes that cutting edge green technology is developed which subsequently is used in all markets to reduce environmental pressure. This leads to the following logic: The better the institutional framework conditions of a country, as indicated by the indicators in section 3, and the higher its green technological capabilities, as measured in section 4 , the more likely a country is to be successful in green innovations. However, this view does not take the perspective into account that regionally segmented markets might exist. On secondary regional markets, exporters might enjoy adversity advantages, exactly because their home country is also characterized by less favorable institutional and technological capabilities such as the country of destination. Thus the analysis in section 3 and 4 is inherently biased towards a perspective which assigns a favorable assessment to the cutting edge performers.

In order to adjust for such a bias, we explicitly look for an empirical indication which supports a regionally segmented market strategy. The starting point is the empirical result that, by and large, the NICs are characterized by weaker institutional frameworks (section 3). Furthermore, even though there has been a strong increase in NICs' publications, there is still a substantial gap with regard to patenting (section 4.2). On the other hand, we see that NICs are becoming increasingly successful in exporting. Thus, we address two questions:

- First, if the NICs have been less successful in building own applied knowledge (as indicated by patent results), do we see an indication that they draw on knowledge from other countries? Unfortunately, data on licensing fees for the green patents we identified is not available. Neither is data available for green FDI inflows. However, NICs can also increase domestic knowledge by cooperating with other countries in knowledge production. Thus, we look at knowledge cooperation patterns by analyzing data on co-patenting in the green technological fields. 
Green technology exports and patents - traditional OECD

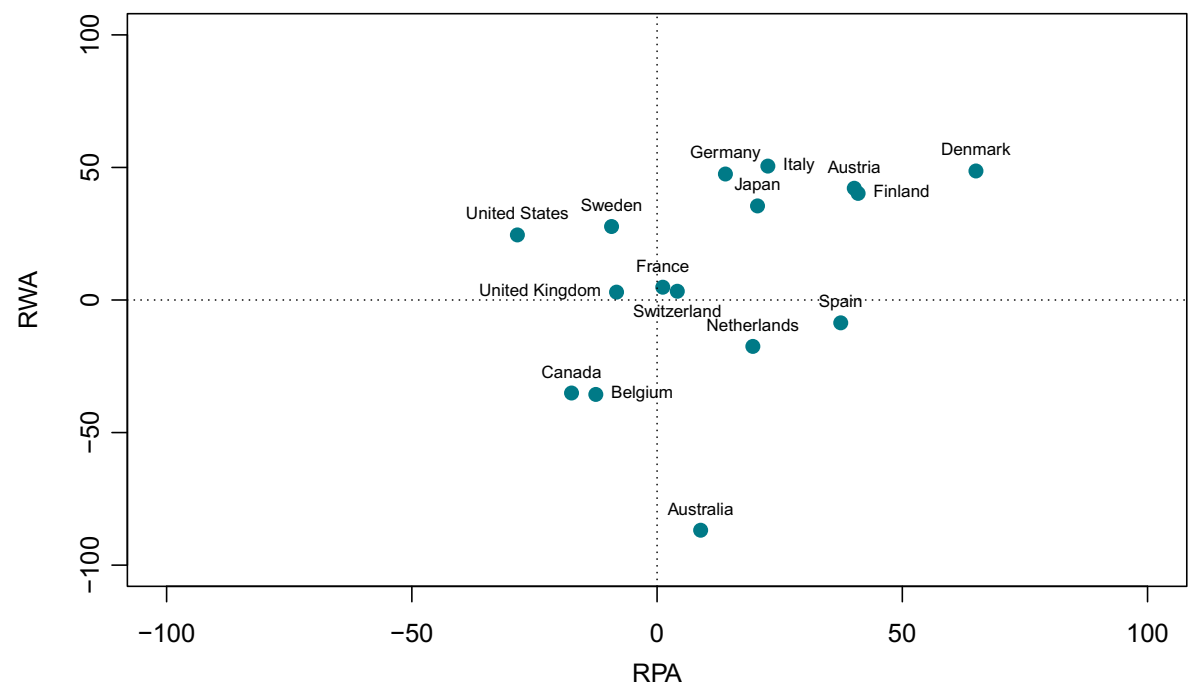

Green technology exports and patents - NICs

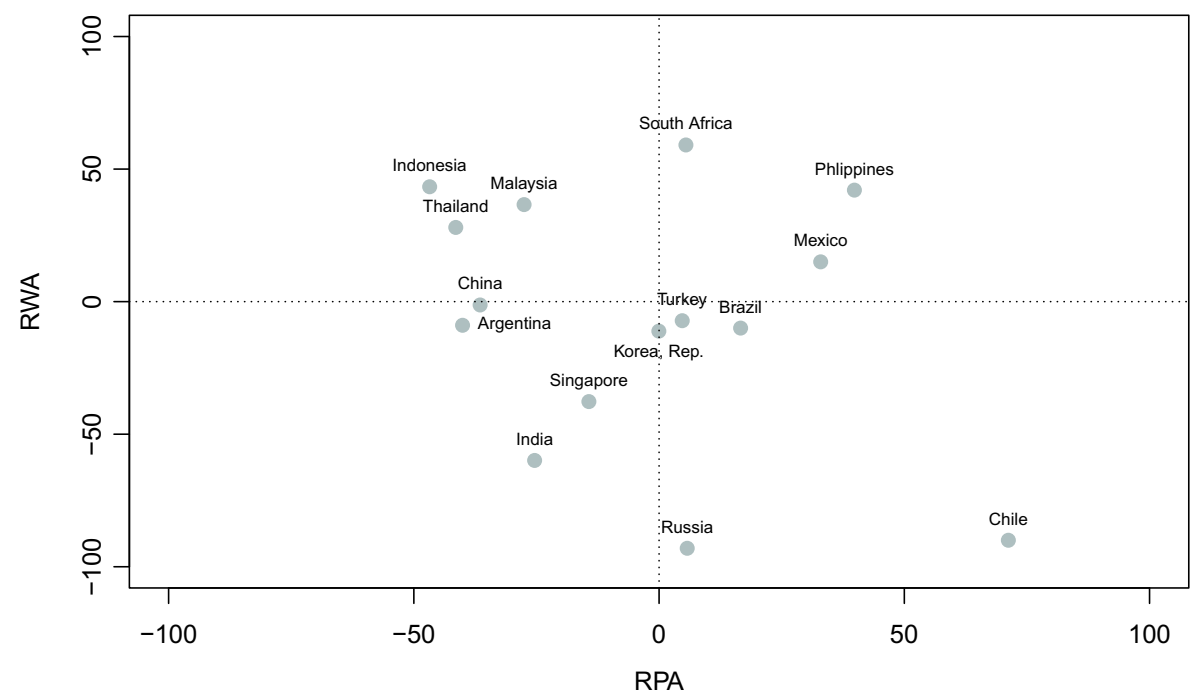

Fig. 10 Export and patent specialization for green technologies in traditional OECD and NICs. Source: own calculation, based on data retrieved from PATSTAT and UN-COMTRADE

- Second, do we see an indication that markets are becoming segmented between primary markets in the North, and secondary markets in the South? Therefore we perform a country to country analysis on trade flows between the countries. This allows us to identify the markets on which countries are specializing, but also yields some indication about capital embodied technology transfer between the countries. 
In order to analyze knowledge cooperation, we first look at the importance of copatenting green technologies compared to overall patenting activity (Fig. 11). By and large, smaller countries, and NICs, tend to have a higher share of co-patents. This seems plausible, as it is more difficult for these countries to find a suitable partner within their own country. Furthermore, the share of co-patents becomes lower for NICs over time. Again, this can be explained by a strong increase of patenting activity within the NICs (albeit from a low level), which makes it more likely to find a suitable domestic cooperation partner. However, the data also indicates country specifics. Japan and Korea, for example, tend to have much lower co-patenting activities. This might be explained by the openness of a country and the general propensity to cooperate internationally.

We also perform a check whether or not co-patenting activity in green patents differs from the pattern for all patents. Given that the development of green technologies tackles global challenges, engaging in co-patenting could be seen as taking up global responsibilities. Indeed, for a number of countries we identify deviations between the shares of total and green co-patents; the latter tend to be higher. However, the differences are not very pronounced, and only give weak support to the hypotheses that the green technologies are seen as a common good (see Fig. 22 in Annex).

The analysis of country-specific co-patenting data also reveals interesting insights. In general, the share of co-patenting with countries of the South has been increasing substantially (Fig. 12). That also holds for the two countries in the sample - Korea and China - which are included in the NIC cluster, and reflects that there are additional NICs beside these two countries which have become attractive co-patenting partners. Furthermore, the increase has been especially strong in Japan and the US. A breakdown of the country-to country co-patenting activity shows that the U.S and Japan have increased their co-patenting activity especially with China (see Table 2 in Annex). Furthermore, China has increased its attractiveness as a co-patenting partner for all countries substantially. Taken together, this supports the hypothesis that the countries of the South are also sourcing new knowledge via cooperation with the North, with China being a particularly successful example of this strategy.

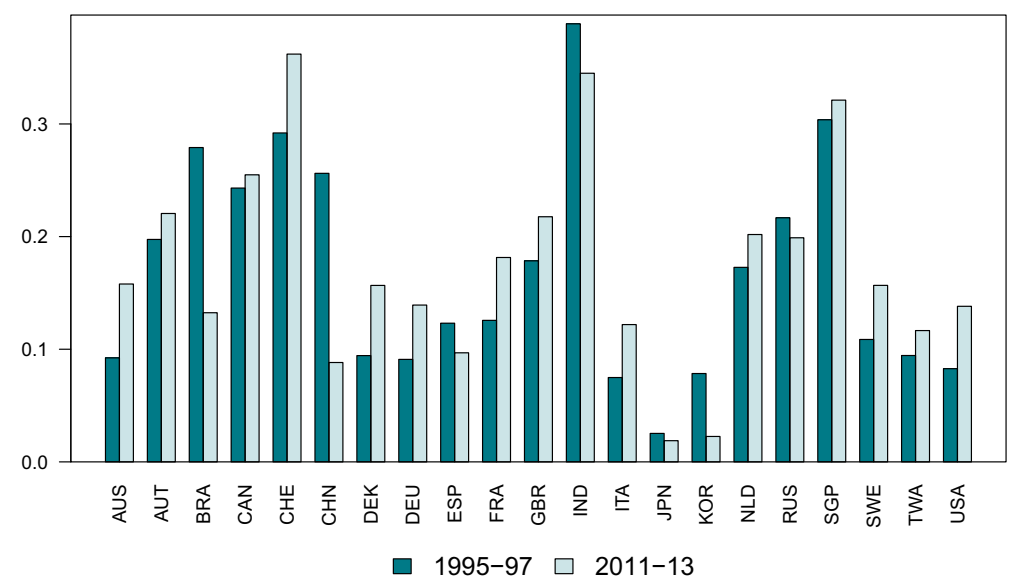

Fig. 11 Share of green co-patents within green patents for selected countries. Source: own calculations, based on data retrieved from PATSTAT 


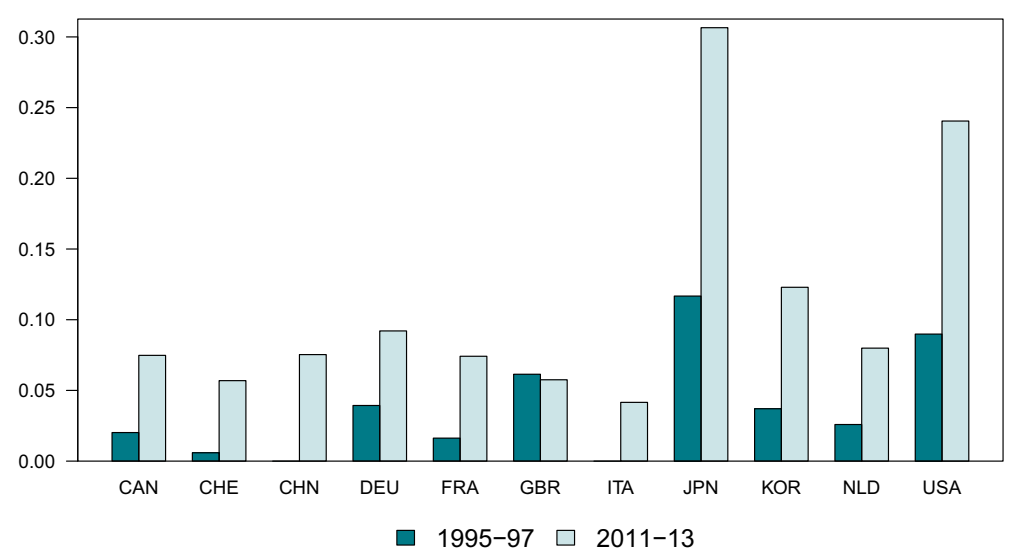

Fig. 12 Share of green co-patents with the south within all green co-patents. Source: own calculations, based on data retrieved from PATSTAT

The export data in section 3 does not differentiate the place of destination of the exports. However, if we want to examine whether the world market for sustainability technologies follows a North-centered development, with NICs trying to catch up and to compete on the same markets, or whether segmented markets with different suppliers-importer patterns are emerging, we have to look at regional markets.

In a first step, we divide the world markets into North and South. Thus, we yield four different supplier-importer segments: exports from the North and exports from the South, both of which are either exported to the North or to the South. In addition to the countries explicitly examined as countries of the North in the previous section, North in this section is defined as all EU-28 countries plus the other traditional OECD-countries. The South consists of all other countries.

Between 2003 and 2008, the exports of all four segments of the markets were growing in absolute terms (Fig. 13, left hand side). However, the growth of exports from the South exceeded the growth of exports from the North, resulting in rising shares of exports from the South to both markets in the South and in the North (Fig. 13, right hand side). The data shows a remarkable change of pattern after 2008. Growth of exports to the North has stalled even in absolute terms, with the South taking a slightly increased share of this market compared to the North. Most of the growth of exports is to markets in the South. Especially the exporters from the South benefitted from this increase: The share of exports from South to South of overall exports has been increasing substantially between 2008 and 2013, and is making up about $20 \%$ of world exports. Perhaps this also reflects an effect of the financial and economic crisis and austerity measures taken after 2008, with governmental budgets for environmental technologies becoming much tighter especially in countries of the EU.

Sections 3 and 4 have shown that countries of the South are developing very differently with regard to capabilities. Thus, in a second step, we isolate China, Korea, Singapore and Mexico from the South and form them into a third segments of countries (CKMS-countries) besides the North and the rest of the South. These four countries, however, are themselves very heterogeneous. There have been different rationales to separate them from the other countries of the South: 

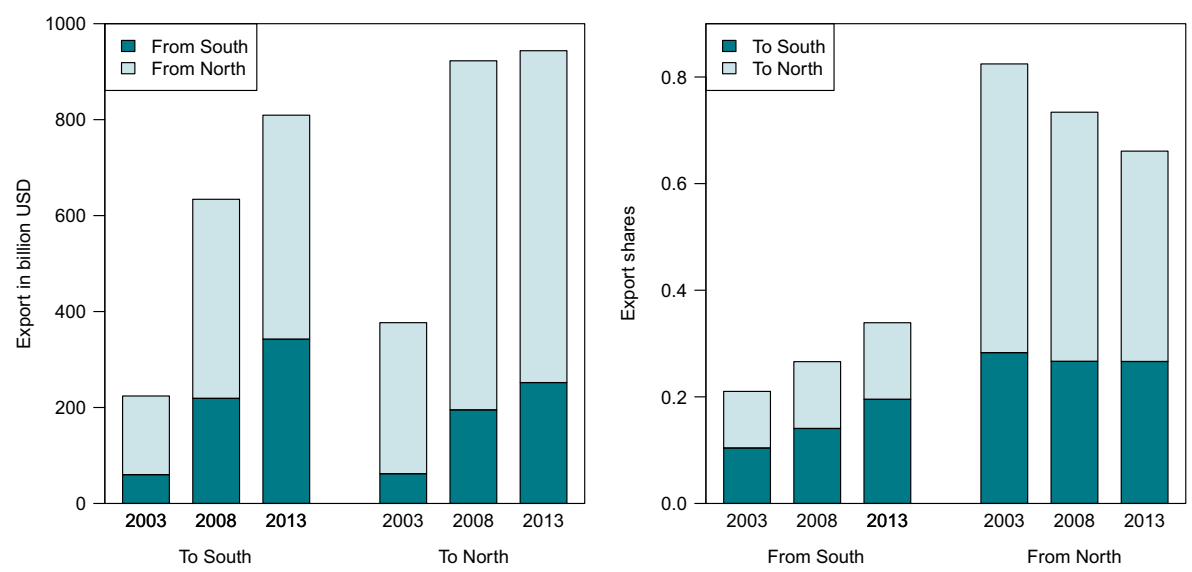

Fig. 13 Exports and export shares of green technologies for countries of the South and North. Source: own calculation, based on UN-COMTRADE data

- China is the biggest exporter from the South. However, its general capabilities are not that highly developed (section 3). Even though it has substantially increased its capabilities in sustainability technologies, it shows a negative patent specialization. Thus, lower domestic technological capabilities would fit a strategy which puts emphasis on using adversity advantages to supply other markets of the South. We isolated China from the other countries of the South in order to be able to compare market shares of China to that regional segment with the market shares of countries for the North.

- South Korea is the second largest exporter of green technologies from the NICs. Among the NICs, it is characterized by an above average general innovation capability. It is already an OECD-member, and is catching-up to the traditional OECD countries quickly. Therefore we separated Korea as well.

- Singapore is characterized by a general innovation capability which is as high as the values for traditional OECD countries. Thus, for exports to Singapore, an adversity advantage does not make much sense, and we therefore took Singapore out of the aggregate South segment as well.

- Mexico is already an OECD-member, and is characterized by a positive patent specialization on green technologies. Most importantly, however, Mexico is highly integrated into the North American markets, which makes it a special case in particular with regard to trade between these Northern markets.

The 3 country groups with the 3 regional markets yields 9 markets segments: exports originating from the North, the CKMS-countries and the South (not including CKMS), and each of these exports being split into going to either markets in the North, the CKMScountries or the South (not including CKMS). However, in contrast to the analysis performed above, the countries of the South do not include China, South Korea, Mexico and Singapore. In order to avoid confusion, this country group is therefore called "other South".

Exports in absolute terms have been steadily increasing to the markets in the "other South" and the "CKMS" countries (Fig. 14 upper part). As already noted above, exports to the North have also been increasing substantially between 2003 and 2008, and have 
stalled more or less since then. The data also reveals a steady increase of the shares going to countries of the "other South" between 2003 and 2013 (Fig. 14 lower part). Since 2008, this increase has been predominantly supplied by exports coming from the CKMScountries, and by increasing trade between the countries of the"other South". The exports from the North to the "other South" have not been increasing since. On the Northern markets, the exports from North to North have been stalling since 2008, too. With this segmentation of the market losing in importance in the world market, this translates in
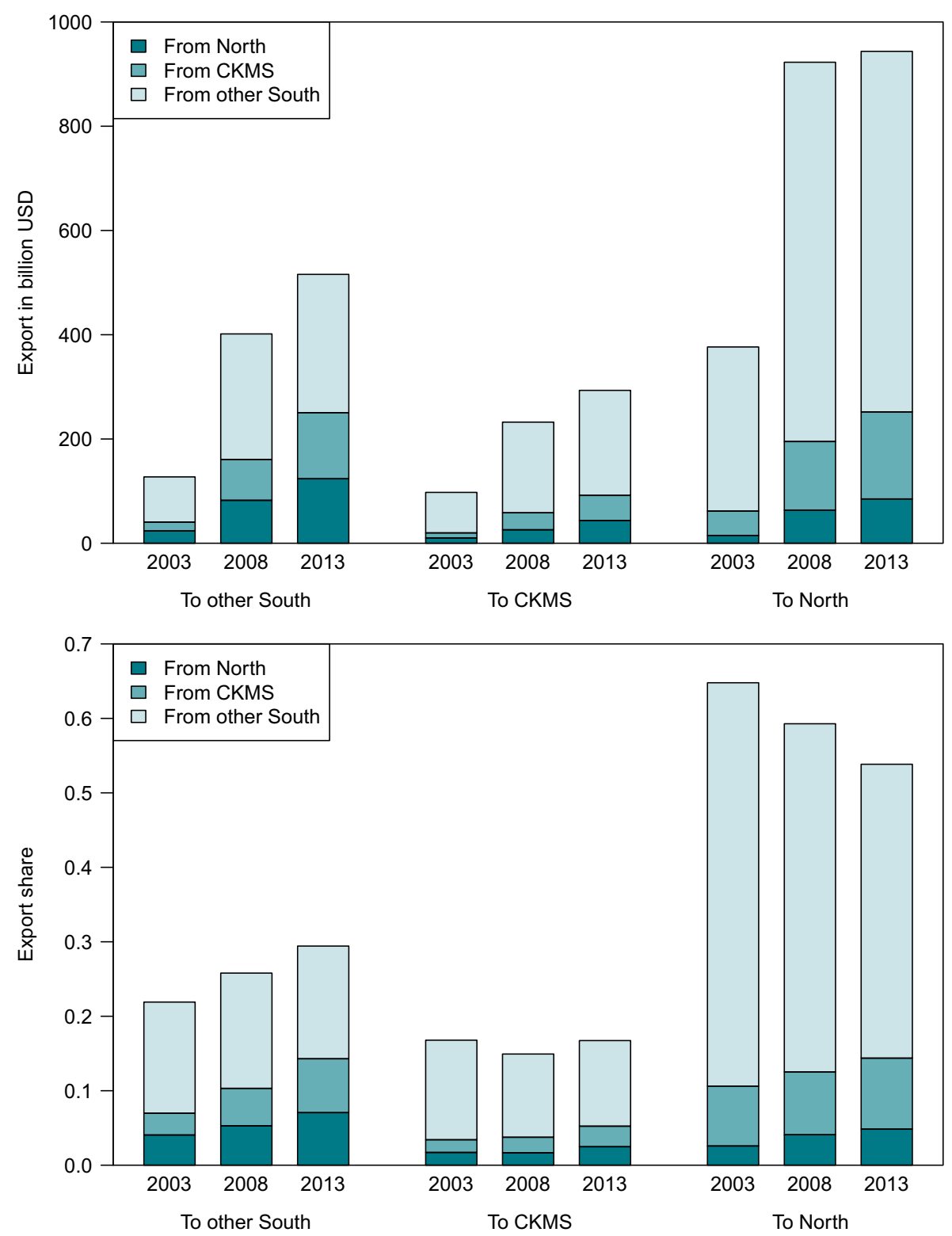

Fig. 14 Exports and world export shares to different regions according to place of origin. Source: own calculation, based on UN-COMTRADE 
reduced world export shares of North-North trade. Exports from the "other South" and CKMS to the North have been increasing, and gained in importance among all exports into Northern markets. Exports between CKMS-countries have been increasing, too. However, exports from the North to CKMS have been increasing constantly, and are still making up the most important component of exports to the CKMS countries. This indicates that the CKMS countries are still importing substantial amounts of cuttingedge green technologies. To sum up the development, the importance of North-North trade has been decreasing. Most notably has been an increase in exports from the CKMScountries going to both the "other South" and other CKMS-countries. In addition, there is evidence that the CKMS still are receiving green technologies from the North, which indicates a capital embodied technology transfer in this category of goods.

In addition to looking at the three aggregated market segments, we look at the regional pattern of exports for single countries (Fig. 15 and Table 3 in Annex). In addition, we construct a specialization index, which indicates on which of the three segments of the market a country is specializing (section 2). The following patterns emerge:

- In all three market segments, China has been doubling its export share between 2003 and 2008. Afterwards, however, China has directed its growth in exports shares predominantly to the other markets of the South. China has become the lead supplier of the "other South" countries, which is also indicated by a strong positive specialization in trade with the "other South" (Fig. 16). At the same time, China has absorbed a lot of exports from countries of the North, and increasingly from South Korea. Thus, China itself seems to follow a double strategy, with absorbing cuttingedge technology from the North in order to compete on markets of the North on the one hand, but increasingly specializing on becoming lead supplier for countries of the "other South" on the other, by using its adversity advantage.

- South Korea has been targeting other segments. It has been increasing its exports especially strongly towards the other South and the CKMS markets, especially China. Singapore's trade pattern leads, by and large, to the same conclusion as that

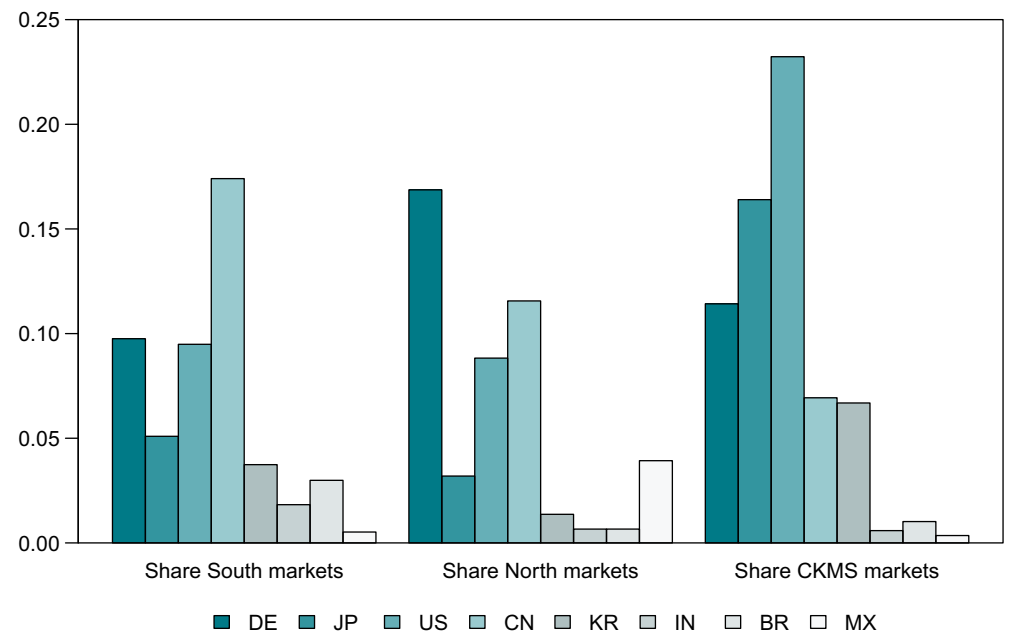

Fig. 15 Export shares and export ratio of country sample in green technology patents 


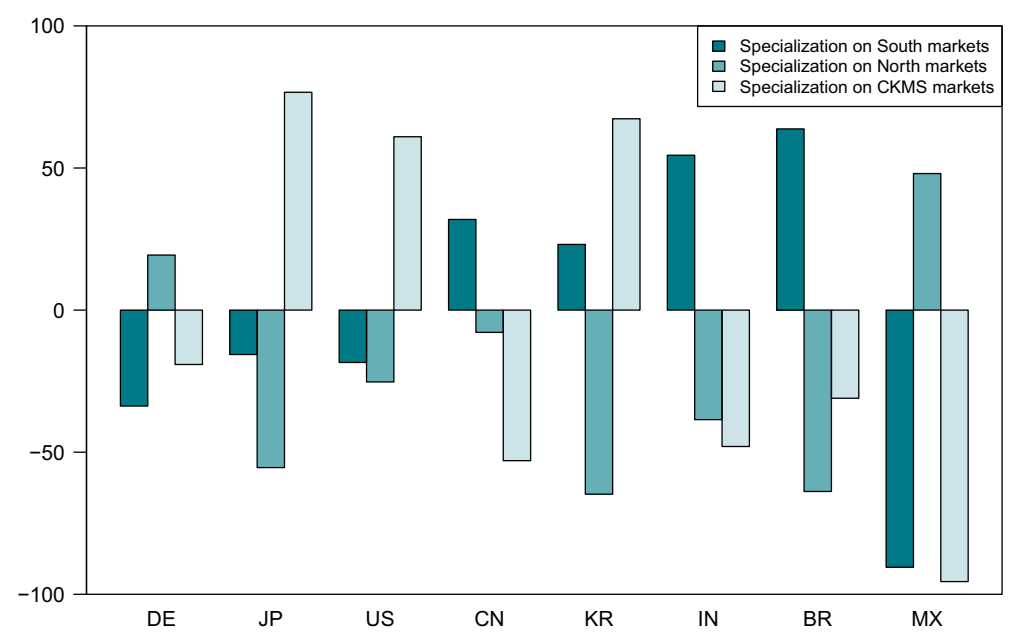

Fig. 16 Export shares and export ratio of country sample in green technology patents. Source: own calculation, based on data from UN-COMTRADE

for South Korea. Thus, we hypothesize that both countries have utilized on supplying China with higher-end technology. Their export pattern in green technologies is increasingly getting close to countries such as Japan.

- The rest of ASIA (without China, South Korea and Singapore) has increased its export shares to all regions. By and large, ASIA keeps specializing in exports to the "other South" countries and to a lesser extent to the CKMS countries. A particularly strong specialization in exports to the "other South" is found for India.

- Mexico is very different from both China and South Korea. It is highly integrated into the US economy, absorbing exports from the US, but also directing major parts of its own exports towards the US. Thus, it is highly specializing on export markets of the North.

- South America is specializing in exports to the "other South" markets. However, it has not been participating in the surge of export shares for countries of the "other South" like China or the other Asian countries. By and large, its export shares have not changed much in each of the three market segments. This also holds for Brazil.

There are also interesting differences between the export patterns of the leading countries from the North:

- Germany is concentrating on supplying the markets in the North, as indicated by its regional specialization profile. It has kept this strategy over the years. Given Germany's positive specialization in both trade and pattern, this can be interpreted as Germany especially targeting the cutting edge technology markets in the North. However, it also means that Germany is not benefiting as strongly as other countries from the surge of markets in the "other South".

- The U.S. is specializing on the CKMS markets. The high positive specialization can be explained by Mexico being an outlet of US exports, but also by high exports going to China.

- Like the U.S., Japan is specializing on the CKMS countries, and even shows a higher regional specialization on this market segment than the U.S. 


\section{Discussion of results and conclusions}

The previous empirical sections have looked how the capabilities of different countries with regard to general and green technology related competences have been evolving. The NICs have been increasing their capabilities substantially. However, by and large, they still possess lower general capabilities, which makes it harder for them to develop cutting edge innovations. With regard to green technological capabilities, NICs, and especially China, have been developing towards a major supplier of new (academic) knowledge. However, even though their patent activity has also increased since the financial crisis, these indicators still clearly point to traditional countries from the North having the highest capabilities. A look at trade data reveals that NICs have a higher share in green technology exports compared to patents. However, it also becomes clear that the countries from both North and South are not homogenous, but differ greatly with regard to their capabilities.

In order to facilitate an overview, we aggregate the data. For each indicator used for country comparison in chapter 3 and 4 , we performed a normalization of the data. We assigned a dimensionless value of 100 towards the indicator value of the best performing country. By building the ratio of each country's indicator value, we were able to transform all indicator values into dimensionless values between 0 and 100 .

In order to facilitate an overview, we aggregated the 3 indicator dimensions used in chapter 3 - general technological capability, governance and corruption prevention into a single composite indicator which we named "general capability". For green technological capabilities, we built three composite indicators:

- In order to look at how important green technology within the country is compared to other fields, we built a composite indicator of literature, patent and export specialization. This measures the importance of green sustainability within the respective country.

- In order to compare the capabilities in green technologies between countries in relative terms to their country size, we built a composite indicator based on patent intensity and export ratio. This measures the relative green technological capability.

- In order to compare the likelihood of innovations being provided by a specific country, we also took the different sizes of their economies into account. Thus, we built a composite indicator which is based on patent intensity, export ratio plus patent and export shares. This measures the green technological and market capability of green technologies.

In building these composite indicators, we attached the same weight for each of the sub-indicators used.

Figure 17 shows that, by and large, the countries of the North have advantages in general capabilities. Only Singapore has reached a comparable level to the leading traditional OECD countries. However, it becomes also clear that the traditional OECD countries differ very much with regard to the relative importance of green sustainability within their innovation system. The same holds for NICs. It is also interesting to see that general capabilities do not correspond to green importance. This evidence can be related to the EKC debate in section 2. In general, countries with higher general capability have a higher GDP per capita. One explanation for the existence of an EKC are the changing preferences in rich societies towards a higher importance of environmental quality compared with other goods (Neumeyer 1998). Thus, it should be 


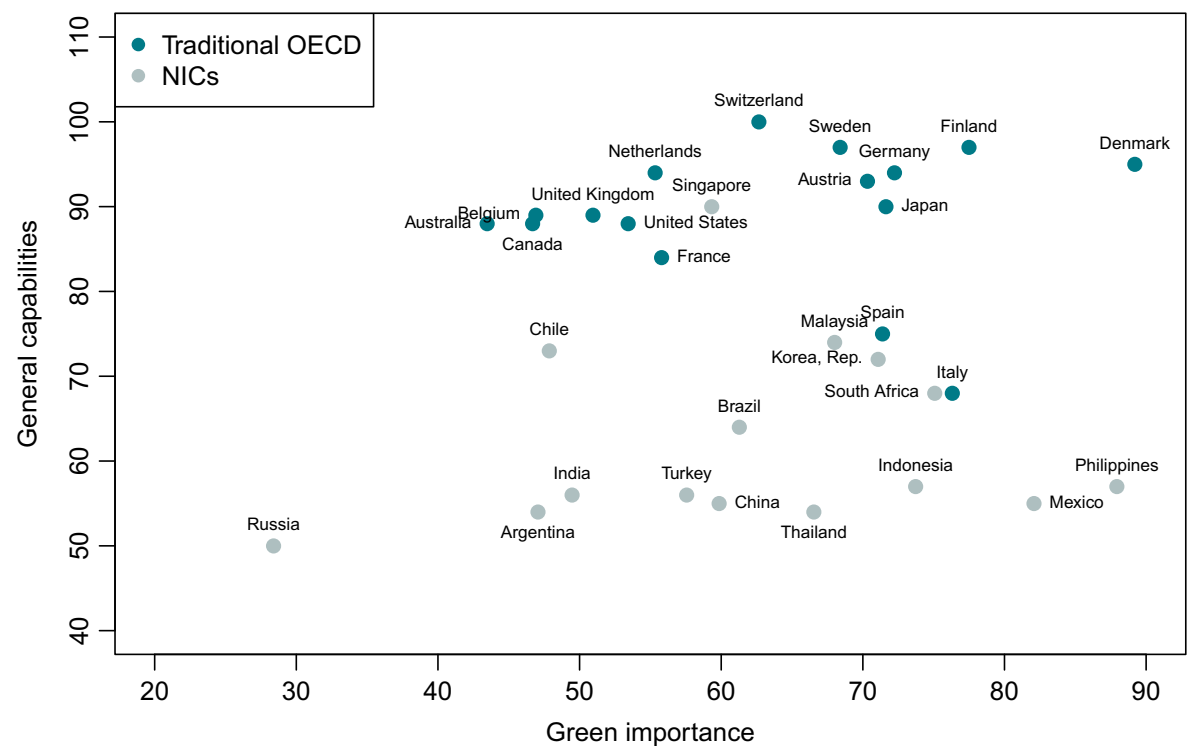

Fig. 17 Mapping of countries with regard to general capabilities and importance of green technological capabilities within the countries. Source: own calculation

expected that such a preference would also show up in our composite indicator of green importance. However, the high level of green importance of some NICs points towards other influences being very important for the emerging pattern. Indeed, the high value in the composite green importance value is supported with especially high positive literature specialization. Thus, it seems to be that especially the research system in NICs is more sensitive to the global challenges.

Figure 18 shows the relationship between the general capabilities and the relative green technological capabilities. With Finland, Denmark, Germany and Austria, four traditional OECD countries show the highest relative green technological capability. However, some OECD countries, e.g. Australia, can also be found at the lower end. We also see that Singapore, Korea and Malaysia are close to the top. In terms of relationship with general capabilities, there is more of a positive relationship, especially if we keep in mind that the NICs with high relative green technological capabilities are also the ones with high general capabilities among the group of NICs. Another reason for the existence of an EKC is seen in a higher availability of green technologies in rich countries (Neumeyer 1998). Thus, the data provides some support for this hypothesis, albeit with the restrictions of only a weak relationship between general and green capabilities.

Figure 19 provides a mapping of general capabilities with green technological and market capabilities of green technologies. The data indicates that in absolute terms, green technological innovations still most likely come from Germany, Japan and - with some distance - from the U.S. Some other middle European countries are also important players. However, it also becomes clear that the positioning is more diverse, with Korea and China being among the top countries as well. Thus, our results points towards the conclusion that innovations for the green SDGs may predominantly come from these countries in the medium term. 


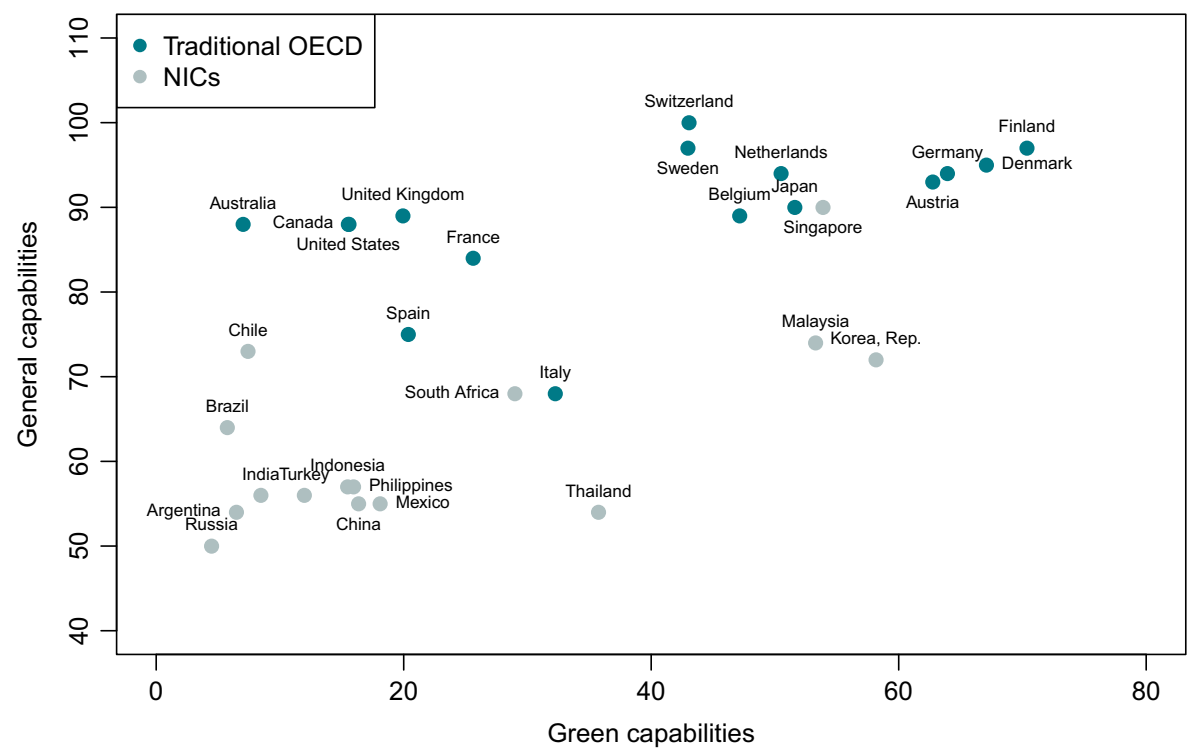

Fig. 18 Mapping of countries with regard to general capabilities and relative green technological capabilities. Source: own calculation

This data has to be interpreted, however, with caution. Especially the following caveats apply:

- The differences between the countries also point towards other factors being important. Thus, our results have to be interpreted with caution, and it will be necessary to also perform country case studies to identify country specific circumstances. Clearly the policy environment, but also availability of natural resources can play a role in the positioning of the countries.

- Small countries are more likely to specialize on a limited set of technologies. Thus, it can be expected that specialization indicators have a bias in favor of small countries.

- The indicators describe a potential for green technological capabilities. A high potential does not translate automatically into a green path of development. The sustainability of applying potentially green technologies is not always guaranteed, and depends, e.g., on the environmental policies.

Trade data was also analyzed with regard to the markets which are predominantly served. The county-to-country analysis of trade, and the dynamics of the last 11 years, sheds light on trade patterns and strategies which are masked by the average data: Not only have export growth rates from the South exceeded the ones from the North, but clearly South-South trade in green technologies is the fastest growing market segment. Countries of the South are pursuing a differentiated strategy: China is following a double strategy, with absorbing technology from the North in order to compete on markets of the North on the one hand, but increasingly specializing on becoming a lead supplier for 


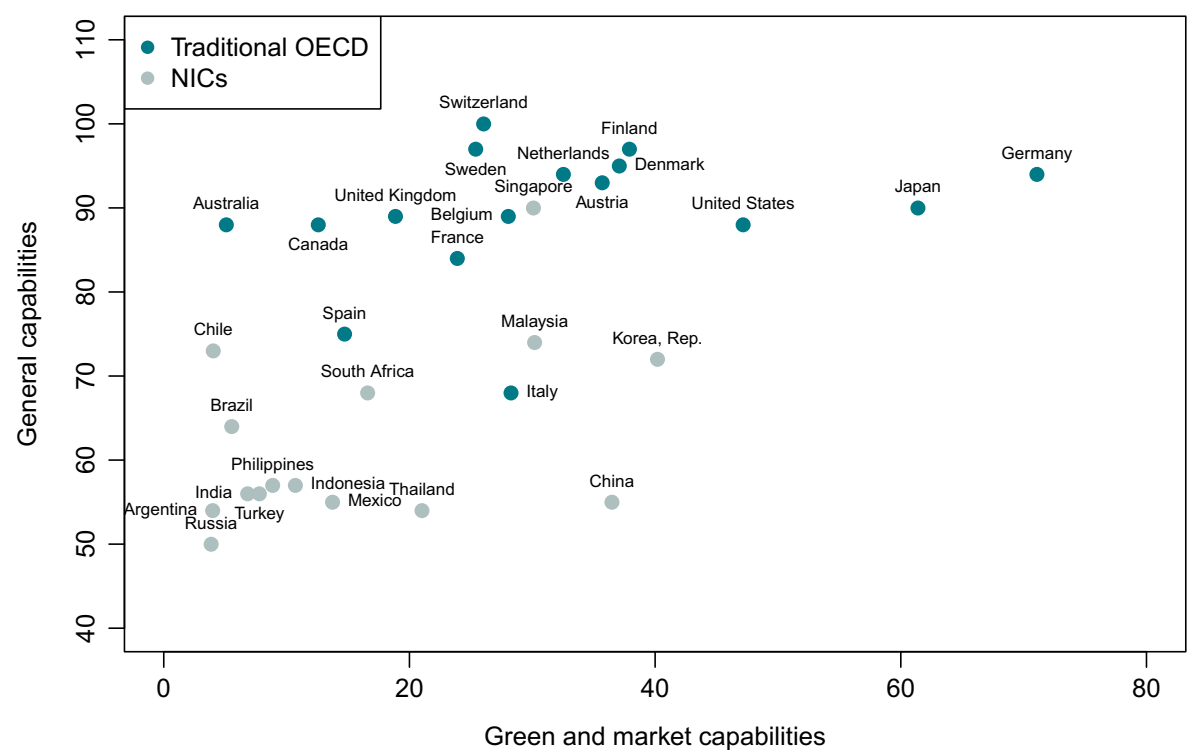

Fig. 19 Mapping of countries with regard to general capabilities and green technological and market capabilities. Source: own calculation

countries of the South on the other hand. Mexico is highly integrated into the US economy. Singapore and South Korea have been catching up and provide technologies especially for China. It has to be seen whether or not both countries will also increase their specialization in green technologies further, which would enable them to forge ahead of more countries from the North. The other technology providers from the South are mainly specializing in supplying other countries from the South.

Summing up, we see that innovations for green SDG-goals will increasingly follow a diverse pattern:

- Cutting edge solutions will most likely continue to be supplied by some of the traditional technology suppliers from the North, perhaps being supplemented by catching-up countries like Singapore or Korea. The classical argument, which sees lead users for superior goods with high income elasticity of demand situated in the North, is accompanied by governmental policies which shape markets for environmental technologies otherwise malfunctioning due to high external costs.

- Green innovations adapted to the framework conditions of the South will become much more important over time. The high importance of green issues within SDGs also reflects the high pressure to reduce the environmental burden in countries of the South. The need for environmental innovations and the build-up of lifesupporting infrastructure go hand in hand. Our empirical analysis shows that especially the research system in the NICs is equipped for the challenge, the innovative business sector, however, much less.

- Nevertheless, exports from the South are increasing. Exports of technologies to the South are already coming increasingly from the South. Furthermore, there is empirical evidence which is consistent with the hypothesis that the markets for 
environmental technologies show a segmented character. We see trends here which are likely to continue.

- Our analysis also indicates a specific transfer function happening around China. China is increasing knowledge within the country (high publication share). Furthermore, it is highly active in co-patenting with the US, and is absorbing high volumes of cutting-edge technologies especially from the US, Japan, South Korea and Singapore. At the same time, it is developing into a major exporter of green sustainability technologies towards countries of the South.

With the countries of the South neither being able to spend as much of their income on the environment as countries of the North, nor having the same framework conditions to absorb high-tech environmental technologies as easily, there is room - and need - for another innovation paradigm such as for example frugal innovations for green sustainability technologies. Whether or not our results are already a sign that NICs are strategically adapting technologies to Southern markets, or whether they reflect mainly a strategy to market sustainability technology based on knowledge no longer used in top-market segments of the North, needs to be analyzed in more depth with case studies in the future. However, the indication that markets do indeed evolve strongly, and that this happens especially in the South, is in itself a promising sign that the innovation systems will be able to develop the innovations necessary to reach the green SDGs.

Acknowledgements This paper draws on research performed within the research project "SINCERE". The financial contribution of the German DFG is acknowledged.

\section{Appendix}

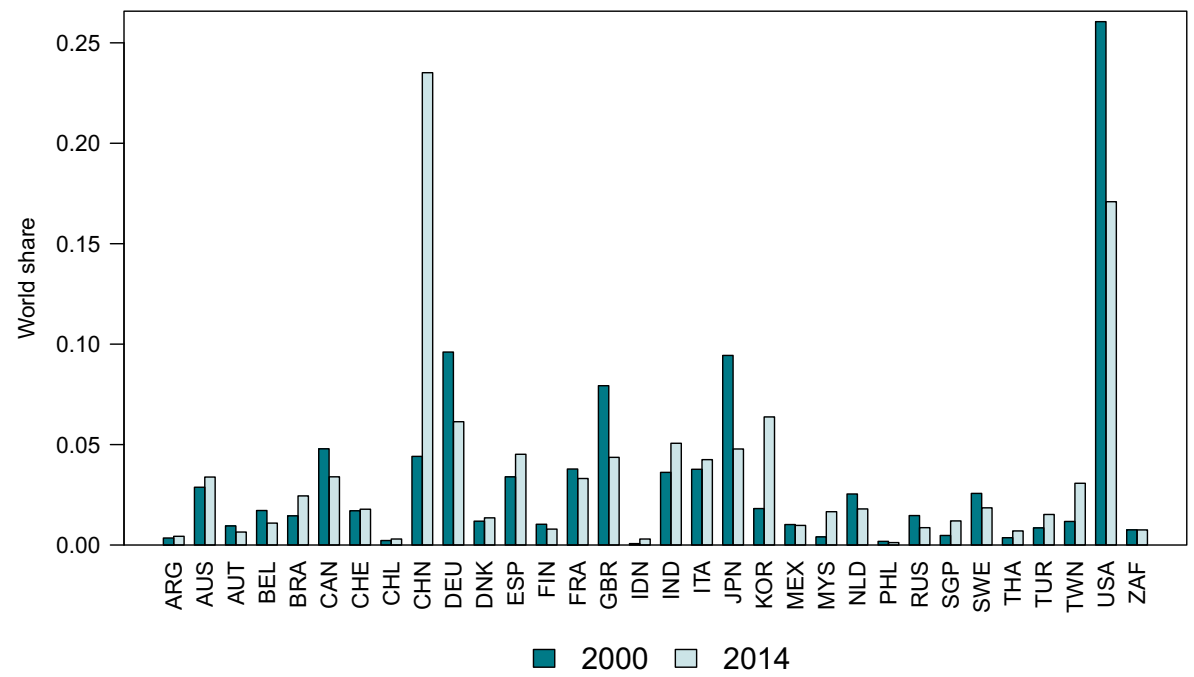

Fig. 20 Development of shares of country sample in green technology publications. Source: own calculations, based on data retrieved from WoS 


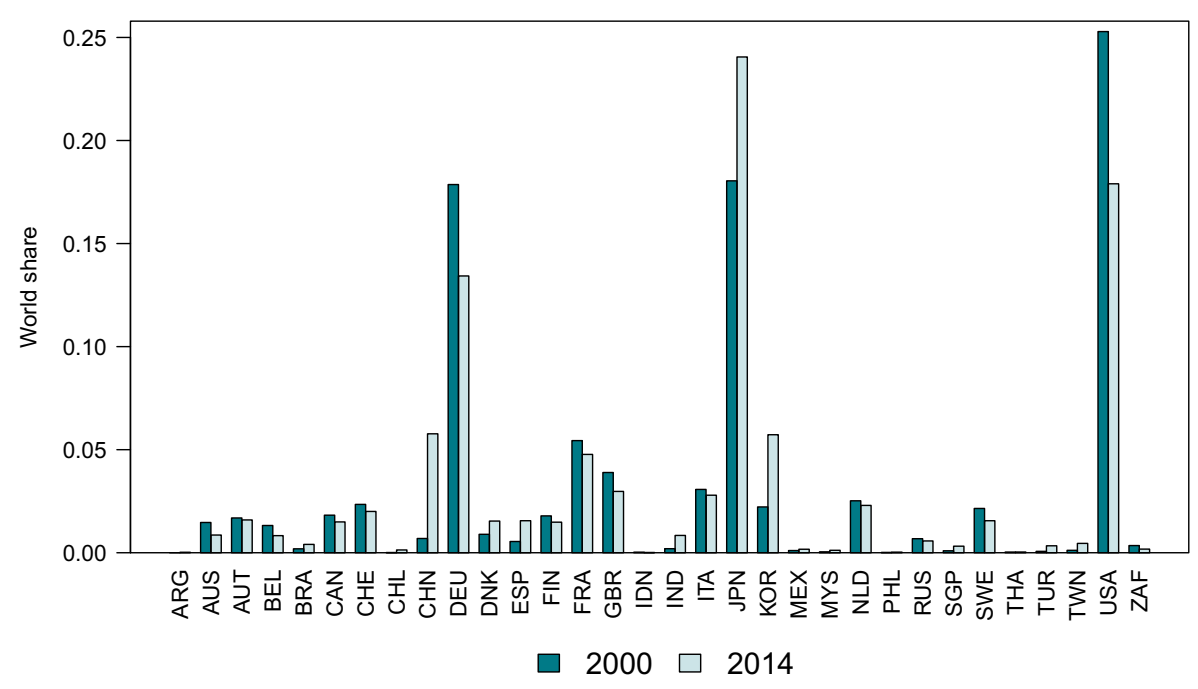

Fig. 21 Development of shares of country sample in green technology patents. Source: own calculation, based on data retrieved from PATSTAT

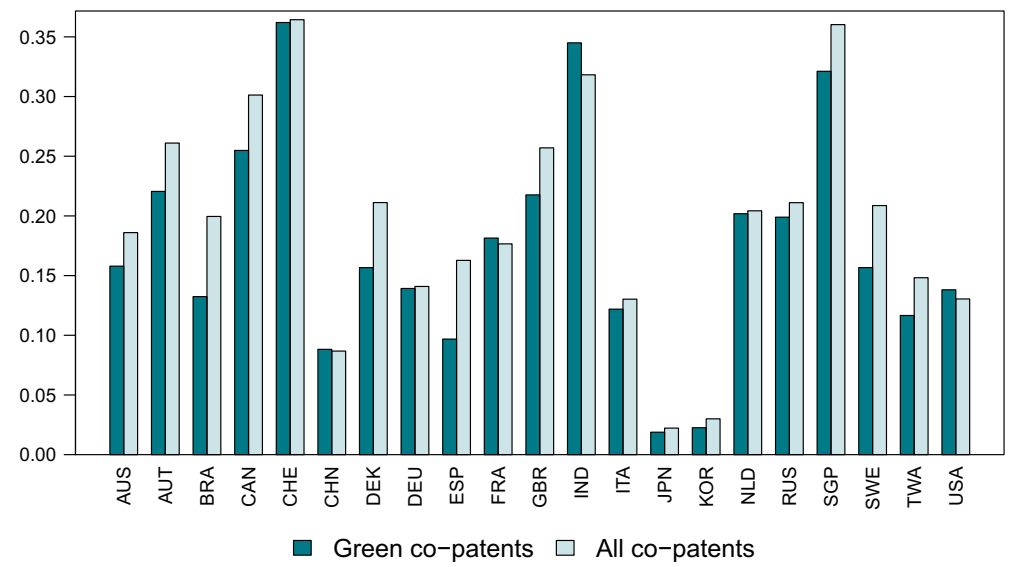

Fig. 22 Share of co-patents within total patents in 2011-2013. Source: own calculation, based on data retrieved from PATSTAT 
Table 2 Share of co-patents of selected countries with other countries in 2011-2013

\section{CN DE $\quad$ FR $\quad$ GB $\quad$ JP $\quad$ KR $\quad$ NL US Other Other \\ South North}

\begin{tabular}{|c|c|c|c|c|c|c|c|c|c|c|}
\hline \multicolumn{11}{|l|}{ 1995-1997 } \\
\hline $\mathrm{CN}$ & & $4 \%$ & $0 \%$ & $22 \%$ & $18 \%$ & $0 \%$ & $0 \%$ & $46 \%$ & $0 \%$ & $10 \%$ \\
\hline $\mathrm{DE}$ & $0 \%$ & & $10 \%$ & $5 \%$ & $2 \%$ & $0 \%$ & $9 \%$ & $24 \%$ & $3 \%$ & $47 \%$ \\
\hline FR & $0 \%$ & $22 \%$ & & $5 \%$ & $2 \%$ & $0 \%$ & $5 \%$ & $11 \%$ & $1 \%$ & $54 \%$ \\
\hline GB & $4 \%$ & $15 \%$ & $7 \%$ & & $2 \%$ & $0 \%$ & $15 \%$ & $23 \%$ & $3 \%$ & $32 \%$ \\
\hline JP & $6 \%$ & $11 \%$ & $4 \%$ & $5 \%$ & & $9 \%$ & $1 \%$ & $35 \%$ & $1 \%$ & $28 \%$ \\
\hline KR & $0 \%$ & $5 \%$ & $0 \%$ & $0 \%$ & $32 \%$ & & $0 \%$ & $32 \%$ & $3 \%$ & $27 \%$ \\
\hline NL & $0 \%$ & $29 \%$ & $7 \%$ & $16 \%$ & $0 \%$ & $0 \%$ & & $21 \%$ & $3 \%$ & $24 \%$ \\
\hline US & $2 \%$ & $21 \%$ & $4 \%$ & $7 \%$ & $5 \%$ & $1 \%$ & $5 \%$ & & $5 \%$ & $50 \%$ \\
\hline $\begin{array}{l}\text { Average importance for partner } \\
\text { country }\end{array}$ & $2 \%$ & $15 \%$ & $5 \%$ & $9 \%$ & $9 \%$ & $1 \%$ & $5 \%$ & $27 \%$ & & \\
\hline \multicolumn{11}{|l|}{ 2011-2013 } \\
\hline $\mathrm{CN}$ & & $14 \%$ & $6 \%$ & $3 \%$ & $11 \%$ & $1 \%$ & $3 \%$ & $41 \%$ & $7 \%$ & $17 \%$ \\
\hline $\mathrm{DE}$ & $4 \%$ & & $12 \%$ & $5 \%$ & $2 \%$ & $1 \%$ & $7 \%$ & $21 \%$ & $4 \%$ & $43 \%$ \\
\hline FR & $3 \%$ & $28 \%$ & & $5 \%$ & $3 \%$ & $0 \%$ & $3 \%$ & $13 \%$ & $4 \%$ & $39 \%$ \\
\hline GB & $2 \%$ & $17 \%$ & $7 \%$ & & $8 \%$ & $0 \%$ & $7 \%$ & $14 \%$ & $3 \%$ & $41 \%$ \\
\hline JP & $14 \%$ & $12 \%$ & $8 \%$ & $14 \%$ & & $10 \%$ & $1 \%$ & $19 \%$ & $5 \%$ & $17 \%$ \\
\hline KR & $3 \%$ & $18 \%$ & $3 \%$ & $0 \%$ & $27 \%$ & & $3 \%$ & $26 \%$ & $9 \%$ & $11 \%$ \\
\hline NL & $2 \%$ & $27 \%$ & $6 \%$ & $9 \%$ & $0 \%$ & $1 \%$ & & $26 \%$ & $5 \%$ & $24 \%$ \\
\hline US & $9 \%$ & $18 \%$ & $5 \%$ & $4 \%$ & $3 \%$ & $2 \%$ & $6 \%$ & & $13 \%$ & $41 \%$ \\
\hline $\begin{array}{l}\text { Average importance for partner } \\
\text { country }\end{array}$ & $5 \%$ & $19 \%$ & $7 \%$ & $6 \%$ & $8 \%$ & $2 \%$ & $4 \%$ & $23 \%$ & & \\
\hline
\end{tabular}

Table 3 Export shares and regional export specialization in green technologies

\begin{tabular}{llllllll}
\hline Country & \multicolumn{2}{l}{ Export shares in market segments } & & \multicolumn{3}{c}{ Export specialization in market segments } \\
\hline & World exports & "Other South" & North & CKMS & "Other South" & North & CKMS \\
DEU & $14 \%$ & $10 \%$ & $17 \%$ & $11 \%$ & -34 & 19 & -19 \\
JAP & $6 \%$ & $5 \%$ & $3 \%$ & $16 \%$ & -16 & -55 & 77 \\
USA & $11 \%$ & $9 \%$ & $9 \%$ & $23 \%$ & -18 & -25 & 61 \\
CHN & $13 \%$ & $17 \%$ & $12 \%$ & $7 \%$ & 32 & -8 & -53 \\
KOR & $3 \%$ & $4 \%$ & $1 \%$ & $7 \%$ & 23 & -65 & 67 \\
IND & $1 \%$ & $2 \%$ & $1 \%$ & $1 \%$ & 54 & -39 & -48 \\
BRA & $1 \%$ & $3 \%$ & $1 \%$ & $1 \%$ & 64 & -64 & -31 \\
MEX & $2 \%$ & $1 \%$ & $4 \%$ & $0 \%$ & -90 & 48 & -96 \\
ZAF & $0 \%$ & $1 \%$ & $0 \%$ & $0 \%$ & 63 & -51 & -62 \\
RUS & $1 \%$ & $2 \%$ & $0 \%$ & $0 \%$ & 73 & -74 & -88 \\
IDN & $2 \%$ & $3 \%$ & $1 \%$ & $3 \%$ & 40 & -45 & 26 \\
SGP & $2 \%$ & $3 \%$ & $1 \%$ & $3 \%$ & 48 & -62 & 35 \\
\hline
\end{tabular}


Open Access This article is distributed under the terms of the Creative Commons Attribution 4.0 International License (http://creativecommons.org/licenses/by/4.0/), which permits unrestricted use, distribution, and reproduction in any medium, provided you give appropriate credit to the original author(s) and the source, provide a link to the Creative Commons license, and indicate if changes were made.

\section{References}

Abramovitz M (1986) Catching up, forging ahead, and falling behind. J Econ Hist 46(2):386-406

Agarwal N, Brem A (2012) Frugal and reverse innovation - Literature overview and case study insights from a German MNC in India and China. In: Bernhard K (ed) 2012 18th International Conference on Engineering, Technology and Innovation (ICE). ICE 2012 conference proceedings : 18-20 June 2012, Munich, Germany. Strascheg Center for Entrepreneurship (SCE), Munich University of Applied Sciences (MUAS), pp. 1-11

Archibugi D, Pietrobelli C (2003) The globalization of technology and its implications for developing countries - windows of opportunity or further burden. Technol Forecast Soc Chang 70(9):861-883

Bell M, Pavitt K (1993) Technological accumulation and industrial growth: contrasts between developed and developing countries. Ind Corp Chang 2(1):157-210

Boehe DM, Qian G, Peng MW (2016) Export intensity, scope, and destinations: evidence from Brazil. Ind Mark Manag 57:127-138

Cohen W, Levinthal D (1990) Absorptive capacity: a new perspective on learning and innovation. Adm Sci Q 35(1):123-133

Cuervo-Cazurra A, Genc M (2008) Transforming disadvantages into advantages: developing-country MNEs in the least developed countries. J Int Bus Stud 39(6):957-979

Dinda S (2004) Environmental Kuznets curve hypothesis: a survey. Ecol Econ 49(4):431-455

Dutt K (2009) Governance, institutions and the environment-income relationship: a cross-country study. Environ Dev Sustain 11(4):705-723

Ekins P (1997) The Kuznets curve for the environment and economic growth: examining the evidence. Environ Plan A 29(5):805-830

Fagerberg J, Godinho M (2005) Innovation and Catching-Up. In: Fagerberg J, Mowery DC, Nelson RR (eds) The Oxford Handbook of Innovation. Oxford University Press, Oxford, pp 514-542

Freeman C, Soete L (2009) Developing science and technology indicators: what can we learn from the past? Res Policy 38(4):583-589

Frietsch R, Schmoch U (2010) Transnational patents and international markets. Scientometrics 82:185-200

Galeotti M, Lanza A, Pauli F (2006) Reassessing the environmental Kuznets curve for CO2 emissions: a robustness exercise. Ecol Econ 57(1):152-163

Gallagher KS (2006) Limits to leapfrogging in energy technologies: evidence from the Chinese automobile industry. Energ Policy 34(4):383-394

Grupp H (1999) Foundations of the Economics of innovation: theory, measurement, and practice. Edward Elgar, Cheltenham

Hoskisson RE et al (2013) Emerging multinationals from mid-range economies: the influence of institutions and factor markets. J Manag Stud 50:1295-1321

Iizuka M (2015) Diverse and uneven pathways towards transitions to low carbon development: the case of solar PV technology in China. Innov Dev 5(2):241-262

Köhler J, Walz R, Marscheider-Weidemann F (2014) Eco-innovation in NICs: conditions for export success with an application to biofuels in transport. J Environ Dev 23(1):133-159

Lall S (1998) Technological capabilities in emerging Asia. Oxf Dev Stud 26(2):213-243

Lee K (2005) Making a technological catch up: barriers and opportunities. Asian J Technol Innov 13(2):97-131

Malerba F, Mani S (eds) (2009) Sectoral Systems of Innovation and Production in developing countries: actors, structure and evolution. Edward Elgar, Cheltenham

Munasinghe M (1999) Is environmental degradation an inevitable consequence of economic growth: tunneling through the environmental Kuznets curve. Ecol Econ 29(1):89-109

Nelson RR (2007) The changing institutional requirements for technological and economic catch up. Int J Technol Learning Innov Dev 1(1):4-12

Neumeyer E (1998) Is economic growth the environment's best friend? ZfU 1998(2):161-176

Peng MW (2012) The global strategy of emerging multinationals from China. Glob Strateg J 2(2):97-107

Quitzow R, Walz R, Köhler J, Rennings K (2014) The concept of "lead markets" revisited: contribution to environmental innovation theory. Environ Innov Soc Trans 10:4-19 
Rasiah R (2008) Conclusions and implications: the role of multinationals in technological capability building and localization in Asia. Asia Pac Bus Rev 14(1):165-169

Rennings K (2000) Redefining innovation - eco-innovation research and the contribution from ecological Economics. Ecol Econ 32:319-332

Smith K (2005) Measuring innovation. In: Fagerberg J, Mowery D, Nelson RR (eds) Oxford Handbook on Innovation. Oxford University Press, Oxford, pp 148-179

Tiwari R, Herstatt C (2012) India - a lead market for frugal innovations? Extending the Lead Market Theory to Emerging Economies Rochester NY

Walz R (2007) The role of regulation for sustainable infrastructure innovations: the case of wind energy. Int J Public Policy 2(1/2):57-88

Walz R, Köhler J (2014) Using lead market factors to assess the potential for a sustainability transition. Environ Innov Soc Trans 10:20-41

Walz R, Marscheider-Weidemann F (2011) Technology-specific absorptive capacities for green technologies in newly industrializing countries. Int J Technol Glob 5(3-4):212-229

World Economic Forum (2015) The global competitiveness report 2014-2015. World Economic Forum, Geneva 